\title{
BİST'te İşsem Gören Faktoring Şirketlerinin Mali Yapılarının Çok Ölçütlü Karar Verme Yöntemleri İle Değerlendirilmesi
}

\author{
Aşır ÖZBEK*
}

\begin{abstract}
$\ddot{O} Z$
Ticaretin yurt içi ve yurt dişl finansmanında önemli bir rol oynayan faktoring şirketlerine duyulan ihtiyaç giderek artmaktadır. Faktoring hizmeti almak isteyen işletmeler için en uygun faktoring şirketini belirlemek, birçok faktörün dikkate alınması gereken çok ölçütlü karar verme (ÇÖKV) problemi olarak görülmektedir. Bu nedenle işletmelerin kendi finansman yapısına uygun faktoring şirketini seçmesi çok önemli hale gelmektedir.

Bu çalışmada Borsa İstanbul'da (BIST) işlem gören 7 adet faktoring firması 2013-2016 yıllarındaki bilanço ve gelir tabloları dikkate alınarak mali açıdan değerlendirilmiştir. Veriler, Kamuya Aydınlatma Platformundan (KAP) elde edilmiştir. Ölçütler, literatür taraması sonucu belirlenmiştir. Şirketlerin değerlendirilmesinde ÇÖKV yöntemlerinden olan, Step-wise Weight Assessment Ratio Analysis (SWARA), Additive Ratio Assessment (ARAS), Multi-Objective Optimization on the basis of Ratio Analysis (MOORA) and Technique for Order of Preference by Similarity to Ideal Solution (TOPSIS) yöntemleri bütünleşik olarak kullanılmıştır. 2013-2016 yılları bütüncül olarak değerlendirildiğinde her ü̧̈ yönteme göre ilk sırayı YKFKT ve GARFA, son sırayı ise SMRFT şirketinin aldiğı görülmüş̧ür.
\end{abstract}

Karar Verme

Anahtar Kelimeler: SWARA, ARAS, MOORA, TOPSIS, Factoring Firması, Çok Ölçütlü

JEL Sinıflandirması: C44, D60, G23

\section{Evaluation of Financial Structures of Factoring Companies Traded in BIST by Multi-Criteria Decision Making Methods}

\begin{abstract}
The need for factoring companies, which play an important role in domestic and foreign financing of trade, is increasing. Determining the most appropriate factoring company for businesses seeking factoring services is a multi-criteria decision-making (MCDM) problem where many factors must be taken into consideration. For this reason, it is very important for the enterprises to choose the factoring company which is best suited to their financing policy.

In this study, 7 factoring companies traded in Istanbul Stock Exchange (BIST) were evaluated in terms their financial aspects taking into consideration the balance sheet and income tables of the years 2013-2016. The data was obtained from the Public Disclosure Platform (KAP). The criteria for the evaluation of the companies were determined as the result of literature review. Step-wise Weight Assessment Ratio Analysis (SWARA), Additive Ratio Assessment (ARAS), MultiObjective Optimization on the basis of Ratio Analysis (MOORA) and Technique for Order of Preference by Similarity to Ideal Solution (TOPSIS) techniques, which are the three of MCDM methods, were used in an integrated way in the direction of rating the aforementioned companies. When the years of 2013-2016 were considered as integrated, it was observed that GARFRA is placed on the top while SMRFT is placed at the bottom according to both methods.
\end{abstract}

\footnotetext{
* Yrd.Doç. Dr. Kırıkkale Üniversitesi Meslek Yüksekokulu, Bilgisayar Tek. Bölümü. email: ozbek@kku.edu.tr
} (Makale Gönderim Tarihi: 14.04.2017 / Yayına Kabul Tarihi: 27.02.2018) 
Key Words: SWARA, ARAS, MOORA, TOPSIS, Factoring Companies, Multi-Criteria Decision Making

JEL Classification: C44, D60, G23

\section{GíRIŞ}

İşletmelerin faaliyetlerini istikrarlı bir şekilde sürdürebilmelerinin temel unsurlardan biri kesintisiz nakit akışıdır. Üretimdeki kalite, satışlardaki verimlilik ve hammadde alımlarındaki maliyetlere işletmeler direk müdahale edip gerektiğinde şirket içi tedbirler alabilirken, tamamen diş etkenlerin kontrolü altındaki tahsilât sürecinde meydana gelen sorunlar, işletmenin geleceğe yönelik planlarını etkilemekte ve nakit akışının aksamasına neden olmaktadır. Nakit akışının kesintisiz olarak devam etmesi, işletmenin geleceğe yönelik yapacağ planlarda en önemli dayanağı olmaktadır (strateji factoring). Özellikle gittikçe artan şiddetli rekabet şartları, firmaların aşırı ölçüde büyümeleri ve büyük ölçekte üretime geçmeleri, mamul çeşitlerinin artması, uluslararası pazarlara açılma, şirket birleşmeleri, para ve sermaye piyasalarındaki gelişmeler ve çok hızlı teknolojik değişmeler, işletmeler için finansmanın öneminin daha çok arttırmıştır (İnal, 2006:108).

Uluslararası ticaretin gelişmesi ile birlikte finansman teknikleri de gelişmiş; dünyada finansman kaynağı gerektiren alanlarda, kaynak olanaklarını zorlayan, sistemin ve imkânların el verdiği ölçüde bunu başarabilen örgüt yapıları ortaya çıkmıştır. Finans kaynaklarının hangi alana yöneltileceği hususunda etkili finansman şirketleri yaygınlaşmış; uluslararası veya yerli nitelikli bir kuruluş tarafından kontrol edilen faktoring işlemleri, ticaret işlemleri ile birlikte, yapılan ticaretin karş1lıklı finansmanı ve uygulanan teknikler önemli rol oynamaya başlamıştır (Özdemir, 2005:194)

Şirketlerin ticari faaliyetlerini gerçekleştirebilmesi için gereksinim duyduğu dış kaynak ihtiyacının karşılanmasında son yıllarda birçok finansman tekniği geliştirilmiştir. Faktoring, işletmelerin ticari faaliyetlerini gerçekleştirebilmesi için gereksinim duyduğu dış kaynak ihtiyacının karşılanmasında kullanılan alternatif bir finansman tekniğidir. $\mathrm{Bu}$ teknik işletmelere finansman kolaylığı sağlamanın yanında, alacaklardan kaynaklanan riski ve muhasebe, tahsilât gibi idari hizmetleri üstlenme fonksiyonlarını da yerine getirmektedir. İç ve dış ticarette işletmelerin faaliyetlerini sağlıklı bir şekilde devam ettirebilmesi için gerekli olan kesintisiz nakit akışı faktoring yöntemi kullanılarak karşılanabilir (Tosun, 2007:1)

İşletmelerin finansman desteği konusunda birlikte çalışacağı finansal kurumları belirlemesi günümüzde gittikçe önem kazanmaktadır. $\mathrm{Bu}$ seçimi sürecinde birbirini etkileyen birçok faktörün dikkate alınması gerekmektedir. $\mathrm{Bu}$ nedenle bu sorun çok ölçütlü karar verme (ÇÖKV) problemi olarak görülmektedir. $\mathrm{Bu}$ açıdan bu tür finansal kurumlarla çalışacak işletmelerin, seçimlerini doğru yapmaları çok önemli olmaktadır.

Bu çalışmada Borsa İstanbul'da (BİST) işlem gören yedi faktoring şirketi, 2013-2016 yıllarındaki bilanço ve gelir tabloları dikkate alınarak 
değerlendirilmiştir. Değerlendirmede kullanılan ölçütler, literatür taraması sonucu belirlenmiştir. Değerlendirme işlemi son yıllarda yaygın olarak uygulanan ÇÖKV yöntemlerinden Step-wise Weight Assessment Ratio Analysis (SWARA), Additive Ratio Assessment (ARAS), Multi-Objective Optimization on the Basis of Ratio Analysis (MOORA) ve Technique for Order Preference by Similarity to Ideal Solution (TOPSIS) yöntemleri ile gerçekleştirilmiştir. Faktoring şirketlerinin değerlendirilmesine yönelik olarak belirtilen dört yöntemin bütünleşik olarak kullanıldığına dair literatürde çalışma bulunamamıştır. Bu açıdan bu çalışmanın literatüre katk1 sağlayacağı düşünülmektedir.

Çalışmanın ikinci bölümünde faktoring kavramı tanıtılmış ve Türkiye'de ve Dünyada faktoring işlemi ele alınmıştır. Üçüncü bölümde literatür araştırılması yapılmış, dördüncü bölümde ise yöntemler tanıtılmıştır. Beşinci bölümde faktoring şirketleri ÇÖKV yöntemleri ile analiz edilmiştir. Son bölümde ise bulgular değerlendirilmiştir.

\section{FAKTORING}

Faktoring kavramı ülkemize ilk olarak 1983 yılında girmiştir. Faktoring ile ilgili çalışmalar ise 1988 yılında bankalar aracılığıyla başlamış ve ilk faktoring işlemi bu yılda gerçekleşmiştir. İlk başladığı dönemlerde düşük bir işlem hacmine sahip olan faktoring işlemleri, yıllar geçtikçe artan bir ivme göstermiştir. Faktoring hizmetlerini genellikle yan sanayi şirketleri; sektör bazında ise gıda, demir, çelik, otomotiv, makine ve teçhizat, tekstil, yedek parça, ticaret, sağlık, büro makineleri, temizlik ve yayıncılık gibi sektörlerde faaliyet gösteren küçük ve orta ölçekli şirketler kullanmaktadır (Özdemir, 2005:209). Faktoring şirketlerinin denetimleri ise 01.01.2006 tarihinden itibaren Bankac1lık Düzenleme ve Denetleme Kurumu (BDDK) tarafindan gerçekleştirilmektedir

Faktoring, mal ve hizmet satışlarından doğan vadeli alacakların temlik yoluyla bir faktoring kuruluşuna devredilmesi ve bu alacakların faktoring kuruluşu tarafından yönetilmesidir. Faktoring işlemi, faktoring şirketi, ticari borçlular (alıcılar) ve mal satan veya hizmet veren bir ticari işletme (satıcı) arasında gerçekleştirilir. Faktoring; finansman, garanti ve tahsilât olmak üzere temelde üç farklı hizmeti işletmelerin ihtiyaçlarına göre birlikte ya da ayrı olarak sunabilir (FKB).

Faktoring işlemlerinin tarafları, yurtdışı ve yurtiçi faaliyetlerine göre farkl111k göstermektedir. Yurtiçi faktoring işlemleri; müşteri, faktoring şirketi ve borçlu olmak üzere 3 taraftan oluşurken; yurtdışı faktoring süreçlerinde ilave olarak yurtdışı faktoring şirketi döngüye dâhil olmaktadır. Tarafları şu şekilde açıklanabilir:

- Müşteri: Mal ya da hizmeti satan taraftır. Faktoring işlemini gerçekleştirmek isteyen taraftır.

- Borçlu: Hizmet veya mal satın alarak borcu ödemekle yükümü olan taraftır.

- Faktoring şirketi: Borçlunun müşteriden mal ya da hizmet satın alması sonucunda oluşacak alacakları kendi üzerine alarak, tahsilâtı üstlenen ve bu alacaklara karşılık ödemelerde bulunan taraftır. 
- Yurtdışı faktoring şirketi: Borçlunun yurtdışında ikamet etmesi durumunda, borçlunun ödeme kabiliyetini takip eden, yurtiçinde bulunan faktoring şirketiyle anlaşmış olan taraftır.

- Faktoring işlemlerinin akışı Şekil l'de verilen çevrimde gösterilmiştir.

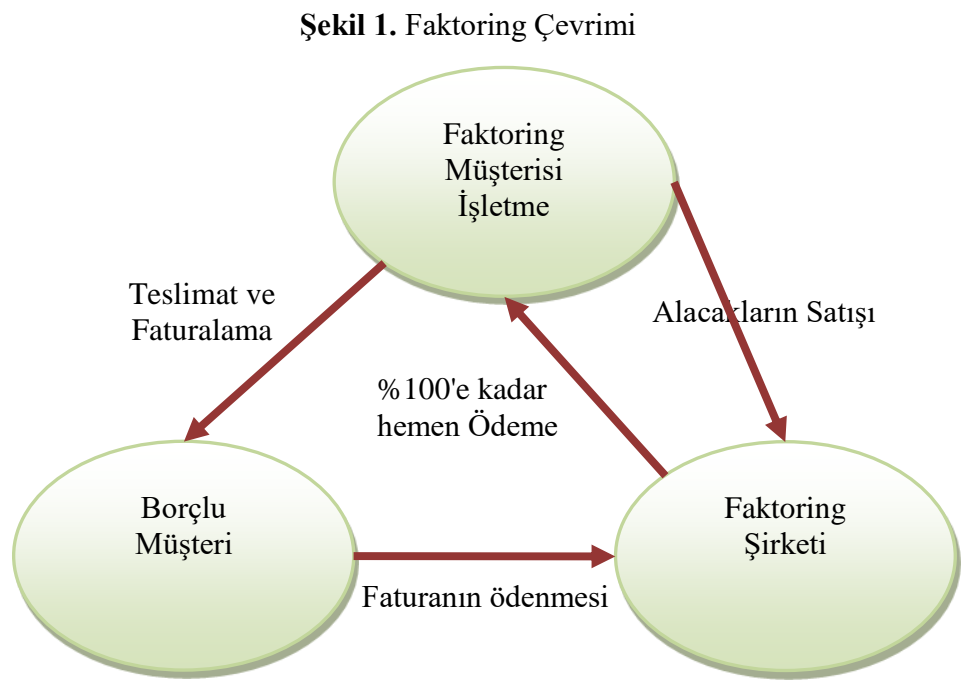

Faktoring uygulamaları; müşteriye, faktoring şirketlerine ve ülke ekonomisine çeşitli avantajlar sağlamaktadır. Bunun yanı sıra bazı dezavantajlar da getirmektedir. Ülkeler arasında vergi ve ticaret yönetmeliklerinin farklılığ nedeniyle faktoring uygulamasının gelişmesi yavaşlamaktadır.

Türkiye'de faktoring sektöründe 2016 yılı sonu itibariyle işlem hacmi yaklaşık olarak 122 milyar 761 milyon TL olarak gerçekleşmiştir. Sektörün aktif büyüklüğü bir önceki y1la göre yüzde 24'lük artışla 33 milyar TL seviyelerinde, özkaynaklar da yüzde 5,6'lık büyüme ile 4,8 milyar TL'ye ulaşmıştır. Faktoring alacakları 31.027 milyon TL, net takipteki alacakları 223 milyon TL, dönem net kâr1 665 milyon TL olarak gerçekleşmiştir. Sektördeki 62 şirket ile faaliyet gösteren sektörün her geçen gün genişleyen müşteri portföyü ise 98 bin rakamını aşmış durumdadır (Blomberg; FKB; FCI).

Dünyada faktoring hacmi 2015 y1l itibariyle 2.595 milyar USD olarak gerçekleşmiştir. Bu rakamın 2.015 milyar USD yurt içi, 580 milyar USD ise yurt dışı faktoring işlemlerinden meydana gelmektedir. Dünya faktöring işlem hacmi her yıl yaklaşık olarak \%11 büyüme göstermektedir. Dünya faktoring hacminin bölgelere göre dağılımı Tablo 1'de verilmiştir (FCI).

Tablo 1. Dünya Faktoring İşlem Hacmi

\begin{tabular}{|l|r|r|r|}
\cline { 2 - 4 } \multicolumn{1}{c|}{} & \multicolumn{3}{c|}{ Milyon USD } \\
\hline Kıta & \multicolumn{1}{c|}{ Yurt İçi } & \multicolumn{1}{c|}{ Yurt Dışı } & \multicolumn{1}{c|}{ Toplam } \\
\hline Afrika & 14.592 & 63 & 14.655 \\
\hline Asya-Pasifik & 415.793 & 236.256 & 652.049 \\
\hline
\end{tabular}




\begin{tabular}{|l|r|r|r|}
\hline Avrupa & 1.381 .546 & 320.632 & 1.702 .178 \\
\hline Orta Doğu-Kuzey Afrika & 11.310 & 1.399 & 12.709 \\
\hline Kuzey Amerika & 91.381 & 18.508 & 109.889 \\
\hline Güney Amerika & 100.555 & 2.694 & 103.249 \\
\hline Genel Toplam & $\mathbf{2 . 0 1 5 . 1 7 7}$ & $\mathbf{5 7 9 . 5 5 2}$ & $\mathbf{2 . 5 9 4 . 7 2 9}$ \\
\hline
\end{tabular}

\section{LITERATUR ARASTTIRMASI}

Banerjee (2003), oran, yıllık ortalama, büyüme hızına göre ortalama oran, bileşik büyüme hızı ve Mann-Whitney U testini kullanarak Hindistan'da faaliyet gösteren 5 faktoring firmasının finansal ve operasyonel performansını ölçmüştür. Yazar, çalışmada faaliyet gösteren faktoring firmalarının finansal ve operasyonel performansını zaman içerisinde arttığını tespit etmiştir. Akel vd. (2010), çalışmalarında BİST'te işlem gören altı adet finansal kiralama firmasının 20052008 yılları arasındaki finansal performanslarını değerlendirmiş ve bu şirketlerinin krizden etkilenme derecelerini ölçmüşlerdir. Ergül ve Akel (2010), BİST'te işlem gören 6 adet finansal kiralama şirketinin mali tablolarını kullanarak 2005-2008 dönemindeki performanslarını TOPSIS yöntemi ile değerlendirmişlerdir. Ravaş ve David (2010) yaptıkları araştırmada, nakit sıkıntısının olduğu uluslararası ekonomik kriz dönemlerinde faktoring yoluyla finansmanın Romen şirketlere uygun bir alternatif fon kaynağı olabileceğini ileri sürmüşlerdir. Ece ve Özdemir (2011), BİST'te işlem gören finansal kiralama ve faktoring sektöründe faaliyet gösteren yedi adet şirketin 2005-2010 yılları performans derecelerini hisse senedi piyasa fiyatındaki yıllık değişimle karşılaş̧ırarak EVA ve TOPSIS yöntemleri ile analiz etmişlerdir. Analizde kullanılan oranlar, ilgili şirketlerin bilanço ve gelir tablolarından elde edilmiştir. Janekova (2012) yaptı̆̆ çalışmada, şirketlerin alternatif fon kaynağı olarak büyük ölçüde ve sürekli olarak faktoring yöntemini kullandıklarını ortaya koymuştur. Ayrıca, dünyada faktoring pazarının gelişme gösterdiğini ve faktoring pazarında faktoring zincirinin önemini vurgulamıştır. Sonuç olarak, şirketler için finansman sağlamada faktoring yönteminin avantaj ve dezavantajlarını özetlemiştir. Günay (2013), Türkiye'de faaliyet gösteren 23 adet leasing şirketinin 2011 y1lı verimlilik ve etkinliklerini Veri Zarflama Analizi (VZA) yöntemi ile değerlendirmiştir. Kaur ve Dhaliwal (2014), Hindistan'da faaliyet gösteren SBI Global Factors ve Canbank Factors şirketlerinin mali performansını değerlendirmişlerdir. Canbank Factors'ün mali performansının, faaliyet kârı, net kâr oranı, özkaynak kârlılığı ve aktif kârlılık ölçütlerinde SBI Global Factors'den daha iyi olduğu ortaya çıkmıştır. Ayrıca hisse başına kazanç, hisse senedi temettü oranı ve hisse başına temettü kalemlerinde de SBI Global Factors'e göre Canbank Factors şirketinin daha iyi durumda olduğunu belirtmiştir. Koch (2015) araştırmasında hissedar grupların, faktoring kurumlarının kârlılı̆̆ına olan etkisini ölçmüş̧ür. Almanya'da yapmış olduğu bu araştırmanın sonucuna göre; kurumun büyüklüğü ve hissedarlar, önemli ölçüde faktoring kurumlarının kârlılığını etkilemektedir. Finansal sahipliğin olduğu faktoring kurumun, herhangi bir kurum ya da işletmede finansal sahipliğin olmadığ 1 faktoring kurumuna göre daha az kârlı olduğu ortaya çıkmıştır. Bağcı ve Esmer (2016), BİST'te işlem gören halka açık faktoring şirketlerinin 2009-2015 yılları arası tercih sıralamasını 
PROMETHEE yöntemi ile belirlemişlerdir. Tercih sıralaması yapılırken faktoring alacakları, faktoring gelirleri, takipteki faktoring alacakları, faktoring borçları ve net dönem kârı/zararı kullanılan ölçütler olarak belirlenmiştir. Çalışma sonucunda tüm y1llar itibariyle en iyi performans gösteren faktoring şirketinin Lider Faktoring olduğu belirlenmiştir.

\section{ARAŞTIRMA YÖNTEMI}

\section{A. SWARA Yöntemi}

Türkçesi Adım Adım Ağırlık Değerlendirme Oran Analizi olarak tercüme edilebilen SWARA; Keršuliené, Zavadskas ve Turskis tarafindan 2010 yılında geliştirilmiş ve bugüne kadar birçok problemin çözümünde uygulanmış, basit ve uzmanlarla birlikte çalışmaya oldukça uygun olan ÇÖKV yöntemidir (Özbek, 2017:43)

Örneğin, mimar seçiminde (Keršulienè ve Turskis, 2011), ürün dizaynında (Zolfani vd.,2013), uygun tedarikçinin seçiminde (Alimardanii, 2013), en uygun makine elemanını belirlemede (Hasan Aghdaie, 2013), güneş enerjisi santrallerinin kurulacağı bölgenin tespitinde (Vafaeipour vd., 2014), personel seçiminde (Karabasevic vd., 2015), bölgesel heyelan tehlikesinin değerlendirilmesinde (Dehnavi vd., 2015), sera yeri tespitinde (Kouchaksaraei vd., 2015) ve sürdürülebilir üçüncü parti tersine lojistik sağlayıcı seçiminde (Mavi vd., 2017) kullanılan ölçüt ağırlıkları SWARA ile belirlenmiştir.

SWARA İ̧slem Adımları (Keršulienè vd., 2010: 243-258)

Adım 1: Ölçütler, uzman görüşü doğrultusunda önem sırasına göre azalan düzende basit olarak sıralanır. Eğe ölçütler birden çok uzman değerlendirecekse, her bir uzmanın münferiden yaptığı değerlendirme azalan düzeyde sıralanır ve geometrik ortalaması alınarak genel bir sıralama elde edilir (Ruzgys vd., 2014:107).

Adım 2: Her bir ölçütün göreceli önem düzeyi belirlenir. Bunun için $j$. ölçütün $(j+1)$. ölçütten ne kadar önemli olduğu belirlenir (Ruzgys vd. 2014:107). Bu değer Keršulienė vd. (2010) tarafindan $s_{j}$ ile gösterilmiş ve Ortalama Değerin Karşılaştırılmalı Önemi olarak adlandırılmıştır.

Adım 3: $k_{j}$ katsayısı aşağıdaki gibi belirlenir.

$k_{j}= \begin{cases}1 & j=1 \\ s_{j}+1 & j>1\end{cases}$

$\operatorname{Adım~4:~} q_{j}$ değişkeni aşağıdaki gibi hesaplanır.

$q_{j}= \begin{cases}1 & j=1 \\ \frac{q_{j-1}}{k_{j}} & j>1\end{cases}$

Adım 5: Değerlendirme ölçütlerinin göreceli ağırlıkları Eşitlik (3)'de formüle edildiği gibi belirlenir. Burada; $w_{j}$, j. ölçütün göreli ağırlığını belirtir.

$$
w_{j}=\frac{q_{j}}{\sum_{k=1}^{n} q_{k}}
$$




\section{B. ARAS Yöntemi}

ARAS yöntemi Zavadskas ve Turskis tarafindan ÇÖKV problemlerinin çözümü için geliştirilmiştir (Zavadskas \& Turskis, 2010: 159-172). Bu yaklaşım karar seçeneklerini çeşitli ölçütler altında fayda fonksiyonu değerine göre sıralayan ÇÖKV yöntemidir. Yöntemde, karar seçeneklerinin fayda fonksiyonu değer oranları optimum karar seçeneklerinin fayda fonksiyon değeri ile karşılaştırılır (Shariati vd., 2014: 411).

ARAS yöntemi birçok farklı ÇÖKV probleminin çözümünde kullanılmıştır. Örneğin mimar seçiminde (Keršulienė ve Turskis, 2011), belirli bir ürün için uygun bir materyali belirlemede (Chatterjee ve Chakraborty, 2012), finansal kurumların sıralanmasında (Reza ve Majid, 2013), bir rüzgar çiftliği için tedarikçilerin seçimi ve sıralanmasında (Chatterjee ve Bose, 2013), otomotiv şirketlerinin finansal performans değerlendirmesinde (Ghadikolaei vd., 2014), tedarikçilerin seçimi, sıralanması ve değerlendirilmesinde (Ghorabaee vd., 2014), araştırma ve teknoloji organizasyonundaki araştırma merkezlerinin performansını değerlendirmekte (Varmazyar vd., 2016) bu yöntem kullanılmıştır.

ARAS İşlem Adımları (Zavadskas \& Turskis, 2010: 159-172)

Adım 1: Karar matrisin oluşturulması. Eşitlik (4)'de gösterildiği gibi karar matrisi oluşturulur. ARAS yönteminde diğer ÇÖKV yöntemlerinden farklı olarak başlangıç karar matrisinde optimal değerlerden oluşan bir satır bulunur.

Burada; $x_{i j}, j$. ölçüte göre $i$. karar seçeneğinin performans değerini göstermektedir. $m$, karşılaştırılacak karar seçeneklerin ve $n$, ölçütlerin sayısını göstermektedir. $x_{0 j}$ ise $j$. ölçütün optimal değerini ifade etmektedir. Optimal değerler karar verici tarafindan da tespit edilebildiği gibi Eşitlik (5a) ve (5b) kullanılarak da belirlenebilir (Zavadskas ve Turskis, 2010:163).

$$
\begin{aligned}
& X=\left[\begin{array}{cccc}
x_{01} & x_{02} & \ldots & x_{0 n} \\
x_{11} & x_{12} & \ldots & x_{1 n} \\
\vdots & \vdots & \vdots & \vdots \\
\vdots & \vdots & \vdots & \vdots \\
\vdots & \vdots & \vdots & \vdots \\
x_{m 1} & x_{n 2} & \ldots & x_{m n}
\end{array}\right] \quad i=0,1, \ldots, m ; j=1,2, \ldots, n \\
& x_{0 j}=\max _{i} x_{i j}, \quad \text { fayda (maksimizasyon)durumu } \\
& x_{0 j}=\min _{i} x_{i j}, \quad \text { maliyet (minimizasyon)durumu }
\end{aligned}
$$

Adım2: Karar matrisin normalize edilmesi. Fayda yönlü ölçütler (6) numaralı ve maliyet yönlü ölçütler ise (7) numaralı Eşitlik kullanılarak matris iki aşamada normalize edilir.

$$
\begin{aligned}
& \bar{x}_{i j}=\frac{x_{i j}}{\sum_{i=0}^{m} x_{i j}} \\
& x_{i j}=\frac{1}{x_{i j}^{*}} ; \quad \bar{x}_{i j}=\frac{x_{i j}}{\sum_{i=0}^{m} x_{i j}}
\end{aligned}
$$


Adım 3: Ăgırlıklandırılmış matrisin oluşturulması. Normalize edilmiş ağırlıklı matrisi $\hat{X}$, Eşitlik (9)'da formüle edildiği gibi oluşturulur. Bütün ölçütlerin normalize edilmiş ağırlıklı değerleri Eşitlik (8) kullanılarak hesaplanır.

$$
\begin{aligned}
& \hat{x}_{i j}=\bar{x}_{i j} w_{j} ; i=0, \ldots, m \\
& \hat{X}=\left[\begin{array}{cccc}
\hat{x}_{01} & \hat{x}_{02} & \cdots & \hat{x}_{0 n} \\
\hat{x}_{11} & \hat{x}_{12} & \cdots & \hat{x}_{1 n} \\
\vdots & \vdots & \vdots & \vdots \\
\vdots & \vdots & \vdots & \vdots \\
\vdots & \vdots & \vdots & \vdots \\
\hat{x}_{m 1} & \hat{x}_{n 2} & \cdots & \hat{x}_{m n}
\end{array}\right] \quad i=0,1,2, \ldots, v e j=1,2, \ldots, n
\end{aligned}
$$
performans değeridir.

Adım4: Optimallik fonksiyonunun hesaplanması. Ağırlıklandırılmış matristen (10) numaralı Eşitlik kullanılarak her karar seçeneğinin optimallik fonksiyon değeri hesaplanır.

$$
S_{i}=\sum_{j=1}^{n} \hat{x}_{i j} ; \quad i=0, \ldots, m ; j=1, \ldots, n
$$

En büyük $S_{i}$ değeri en iyisi ve en küçük $S_{i}$ değeri ise en kötüsü olarak değerlendirilir (Zavadskas ve Turskis, 2010:165).

Adım 5: Fayda derecesinin hesaplanmast ve siralamanin yapılmast. Fayda derecesi $K_{i}$, bir karar seçeneğinin optimallik fonksiyon değeri $S_{i}$ ile en iyi karar seçeneğinin optimallik fonksiyon değerine $S_{0}$ oranlanması ile bulunur. Bu durum Eşitlik (11) ile ifade edilmiştir.

$$
K_{i}=\frac{S_{i}}{S_{0}} ; i=0, \ldots, m
$$

$K_{i}[0,1]$ aralığına bir değer alır ve büyükten küçüğe doğru sıralanır. İlk sıradaki karar seçeneği performansı en iyi olandır.

\section{MOORA Yöntemi}

MOORA yöntemi Brauers ve Zavadskas tarafindan 2006 yılında geliştirilmiştir. Çok amaçlı optimizasyon yöntemi olan MOORA, yeni bir yöntem olup literatürde farklı modelleri yer almaktadır.

MOORA yöntemi birçok farklı ÇÖKV probleminin çözümünde başarılı bir şekilde uygulanmıştır. Örneğin özelleştirme uygulamalarında (Brauers ve Zavadskas, 2006), yol tasarımı optimizasyonunda (Brauers vd., 2008), binalarda 1s1 kaybına karşılık farklı pencere ve duvar tasarım alternatiflerine karar vermede (Kracka vd., 2010), üretim sistemlerinin seçiminde (Chakraborty, 2011), Avrupa Birliği üyelerinin performanslarının Lizbon ölçütlerine göre sıralamasında (Brauers vd., 2011), malzeme seçiminde (Karande ve Chakraborty, 2012), zeki üretim sistemlerinin belirlenmesinde (Mandal \& Sarkar, 2012), kaynak işlemi parametrelerinin optimizasyonunda (Gadakh vd. 2013), akademik birim yönetici seçiminde (Özbek, 2015a), arıtma teknolojisini belirlemede (Liu vd. 2014), 2008- 
2009 yılları arasında 20 Avrupa ülkesindeki inşaat sektörü değerlendirilmesinde (Bauer vd., 2014), liman yerini tespit etmede (Causa ve Brauers, 2014) ve Türkiye'de faaliyette bulunan bankaların performansını ölçmede (Özbek, 2015b; Şişman ve Doğan, 2016) MOORA yöntemi uygulanmıştır.

MOORA İşlem Adımları (Brauers ve Zavadskas, 2012:1-25)

Adım 1: Başlangıç matrisin oluşturulması. Bu matris, satırları karar seçeneklerini ve sütunları ölçütleri gösterecek şekilde oluşturulur. Burada $x_{i j}, i$. seçeneğin $j$. ölçüte göre performans değerini gösterir. $M$ karar seçeneklerinin, $n$ ise ölçütlerin sayısını gösterir.

Adım 2: Matrisin normalize edilmesi. Matrisin normalize edilmesi ölçütlerin maksimizasyon ya da minimizasyon yönlü olup olmadığına bakılmaksızın Eşitlik (12) kullanılarak yapılır.

$$
x_{i j}{ }^{*}=\frac{x_{i j}}{\sqrt{\sum_{i=1}^{m} x_{i j}^{2}}}
$$

Adım 3:Karar seçeneklerinin performansının hesaplanması. Normalize edilmiş maksimizasyon performans değerleri toplamından minimizasyon performans değerleri toplamı çıkarılır. Bu işlem Eşitlik (13)'da gösterildiği gibi formüle edilir. $w_{\mathrm{i}}$, ölçütlerin önceliklerini göstermektedir.

$$
y_{i}^{*}=\sum_{j=1}^{g} w_{j} x_{i j}^{*}-\sum_{j=g+1}^{n} w_{j} x_{i j}^{*}
$$

$g$, maksimize edilecek, $(n-g)$, minimize edilecek ölçütlerin sayısını ve $y_{i}^{*}$ ise $i$. seçeneğin tüm ölçütlere göre normalize edilmiş değerini ifade etmektedir. $y_{i}^{*}$ değerleri büyükten küçüğe doğru sıralanır. $y_{i}^{*}$ sıralamasına göre birinci sıradaki seçenek en uygun seçenek olarak belirlenir.

\section{TOPSIS Yöntemi}

Pozitif-ideal çözüme (PİÇ) en kısa mesafe ve negatif-ideal çözüme (NIÇ) en uzak mesafedeki seçeneği belirlemeyi amaçlayan yöntem, Hwang ve Yoon tarafından 1980 yılında geliştirilmiş ve birçok alanda uygulanmıştır. PİÇ en yakın ve NiÇ ise en uzak mesafede olan seçenek en iyi alternatif olarak kabul edilmektedir (Cheng vd., 2002:982).

Özbek ve Eren (2013) en uygun hizmet sağlayıcı firmayı belirlemede, Xi ve Zhang (2011) personel seçiminde, Ravi (2011) üçüncü parti tersine lojistik firmayı belirlemede, Chu ve $\mathrm{Su}$ (2012) şehirlerin tahliyesinde sabit deprem sığınakların tespitinde, Pazand vd. (2012) maden yataklarının araştırılmasında kullanılan maden potansiyelinin haritalanmasında, Özbek $(2013 ; 2014)$ öğrenim yönetim sistemi performans değerlendirmesi ve Sivil Toplum Kuruluşlarında yöneticilerin belirlenmesinde, $\mathrm{Li}$ (2016) Çin Devletinin 2015 yllındaki çalışmalarına internet kamuoyunun etkisini değerlendirmede, Mousavi-Nasab ve Sotoudeh-Anvari (2017) malzeme seçim probleminde, Sindhu vd. (2017) güneş enerjisi tesisatı için uygun alanın seçiminde TOPSIS yöntemini kullanmıştır. Awasthi vd. (2011) sürdürülebilir ulaşım sistemlerinin değerlendirilmesinde, 
Chamodrakas ve Martakos (2012) heterojen kablosuz ağlar arasında enerji verimli ağ seçiminde, Özbek (2015c) ve Arıkan Kargı (2016) tedarikçi seçiminde bulanık TOPSIS yöntemini uygulamıştır.

TOPSIS İşlem Adımları (Baležentis ve Streimikiene, 2017:862-871)

Adım 1: Karar matrisinin oluşturulması: Karar seçeneklerini ve ölçüt değerlerini yansıtan karar matrisi oluşturulur. Matrisin satırlar, karar seçeneklerini, sütunlar ise ölçütleri gösterir.

Adım 2: Standart karar matrisinin oluşturulması: Karar matrisinden (14) numaralı Eşitlik kullanılarak standart karar matris oluşturulur.

$$
\begin{aligned}
& \forall d_{i j} \neq 0: r_{i j}=\frac{d_{i j}}{\sqrt{\sum_{k=1}^{m} d_{k j}^{2}}} \forall_{i}=1, \ldots, m \quad \forall_{j}=1, \ldots, n \\
& \forall d_{i j}=0: \text { ise } r_{i j}=0 ; \quad \forall_{i}=1, \ldots, m, \quad \forall_{j}=1, \ldots, n
\end{aligned}
$$

Adım 3: Ağırlıklı standart karar matrisin oluşturulması: Ölçüt ağırlıkları $\boldsymbol{w}_{\boldsymbol{i}}$ standart matrisin ilgili elemanı ile çarpılarak ağırlıklandırılmış matris oluşturulur.

Adım 4: Pozitifideal $\left(\boldsymbol{A}^{*}\right)$ ve negatif ideal $\left(\boldsymbol{A}^{-}\right)$çözümlerin oluşturulması: Ağırlıklandırılmış karar matrisinden $\boldsymbol{A}^{*}$ ve $\boldsymbol{A}^{-}$adında iki farklı sanal çözüm kümesi elde edilir. Değerlendirme ölçütleri fayda cinsinden ise, $\boldsymbol{A}^{*}$ matrisin en yüksek değerinden oluşurken; $\boldsymbol{A}^{-}$, en düşük değerden oluşmaktadır. Değerlendirme ölçütleri maliyet cinsinden ise bu durumda $\boldsymbol{A}^{*}$, matrisin en küçük değerinden oluşurken, $\boldsymbol{A}^{-}$, en büyük değerinden oluşmaktadır.

İdeal çözümler, (15) ve (16) numaralı Eşitlikler kullanarak hesaplanabilir. Her iki formülde de $J$ fayda, $J$ ' ise maliyet değerini göstermektedir (Özbek, 2014:4).

$$
\begin{aligned}
& A^{*}=\left\{\left(\max _{i} v_{i j} \mid j \in J\right),\left(\min _{i} v_{i j} \mid j \in J^{\prime}\right) i=1, \ldots, m\right\} \\
& A^{*}=\left\{v_{1}^{*}, v_{2}^{*}, \ldots, v_{j}^{*}, \ldots, v_{n}^{*}\right\} \\
& A^{-}=\left\{\left(\min _{i} v_{i j} \mid j \in J\right),\left(\max _{i} v_{i j} \mid j \in J^{\prime}\right) i=1, \ldots, m\right\} \\
& A^{-}=\left\{v_{1}^{-}, v_{2}^{-}, \ldots, v_{j}^{-}, \ldots, v_{n}^{-}\right\} \\
& J=\{j=1, \ldots n \mid \text { olçütler fayda türünden }\} \\
& J^{\prime}=\{j=1, \ldots n \mid \text { ölçütler maliyet türünden }\} \\
& J \cap J^{\prime}=\emptyset \wedge J \cup J^{\prime}=\{1, \ldots, n\}
\end{aligned}
$$

Adım 5: Ayırım ölçülerinin hesaplanması: TOPSIS'de her bir alternatif $\boldsymbol{A}_{\boldsymbol{i}}$ için ideal ayırım $\boldsymbol{S}_{\boldsymbol{i}}^{*}$ ve negatif ideal ayırım $\boldsymbol{S}_{\boldsymbol{i}}^{-}$olmak üzere iki ayırım ölçüsü hesaplanır. $J$ seçeneğinin PİÇ'e uzaklığı $\boldsymbol{S}_{\boldsymbol{i}}^{*}$, (17) numaralı ve NIÇ’den uzaklığı $\boldsymbol{S}_{\boldsymbol{i}}^{-}$ ise (18) numaralı Eşitlik kullanılarak hesaplanır.

$$
S_{i}^{*}=\sqrt{\sum_{j=1}^{n}\left(v_{i j}-v_{j}^{*}\right)^{2}} \quad \forall_{i}=1, \ldots, m
$$




$$
S_{i}^{-}=\sqrt{\sum_{j=1}^{n}\left(v_{i j}-v_{j}^{-}\right)^{2}} \quad \forall_{i}=1, \ldots, m
$$

Adım 6: Ideal çözüme göreli yakınliğın hesaplanması: $\boldsymbol{S}_{\boldsymbol{i}}^{*}$ ve $\boldsymbol{S}_{\boldsymbol{i}}^{-}$ölçüleri kullanılarak her bir alternatif için PiÇ’e olan göreli yakınlığ $\boldsymbol{C}_{\boldsymbol{i}}^{*}$, (19) numaralı Eşitlik kullanılarak hesaplanır. PIÇ’e en yakın mesafede bulunan alternatif en uygun seçenek olarak belirlenir.

$$
C_{i}^{*}=\frac{S_{i}^{-}}{S_{i}^{-}+S_{i}^{*}} \quad 0 \leq C_{i}^{*} \leq \forall_{i}=1, \ldots, m
$$

\section{BULGULAR ve DEĞERLENDİRME}

Bu çalışmada BİST'de işlem gören 7 adet faktoring şirketi, 2013-2016 yıllarına ait bilanço ve gelir tabloları dikkate alınarak 12 ölçüte göre değerlendirilmiştir. Takipteki Alacaklar, Faktoring Borçları ve Diğer Borçlar ölçütleri maliyet yönlü iken diğer ölçütler fayda yönlü olarak belirlenmiştir. Ölçütlerin tercih sıralaması ARAS, MOORA ve TOPSIS yöntemi ile gerçekleştirilmiştir. Ölçütler, literatür taraması neticesinde tespit edilmiş ve ağırlıkları ise SWARA yöntemi ile belirlenmiştir. Ölçütlerin uzmanlar tarafından yapılan sıralamaları ve yönleri Tablo 2'de verilmiştir.

\section{A. SWARA Yöntemi}

Literatür taraması ile tespit edilen ölçütler ilk olarak sahasında uzman 6 kişi tarafindan önem sırasına göre yukarıdan aşağıya doğru basit olarak sıralanmıştır. Daha sonra bu sıralamaların geometrik ortalaması alınarak yeniden azalan sırada sıralanmıştır (Tablo 2).

Tablo 2. Ölçütlerin Uzmanlara Göre Siralamas1

\begin{tabular}{|l|c|c|c|c|c|c|c|c|c|}
\hline Ölçüt & Sembol & Yön & KV1 & KV2 & KV3 & KV4 & KV5 & KV6 & G.ORT \\
\hline Faktoring Gelirleri & K1 & + & 3 & 1 & 1 & 1 & 9 & 1 & 1,73 \\
\hline Faktoring Alacaklar1 & K2 & + & 4 & 2 & 2 & 2 & 8 & 3 & 3,03 \\
\hline Diğer Alacaklar & K3 & + & 8 & 7 & 7 & 8 & 10 & 6 & 7,57 \\
\hline Takipteki Alacaklar & K4 & - & 2 & 12 & 10 & 11 & 7 & 10 & 7,55 \\
\hline Duran Varlıklar & K5 & + & 7 & 8 & 9 & 9 & 4 & 8 & 7,25 \\
\hline $\begin{array}{l}\text { Maddi Olmayan Duran } \\
\text { Varlıklar }\end{array}$ & K6 & + & 12 & 6 & 8 & 12 & 5 & 9 & 8,23 \\
\hline Toplam Aktifler & K7 & + & 9 & 4 & 6 & 5 & 3 & 7 & 5,32 \\
\hline Alınan Krediler & K8 & + & 6 & 10 & 5 & 6 & 6 & 5 & 6,15 \\
\hline Faktoring Borçlar1 & K9 & - & 10 & 9 & 11 & 7 & 11 & 11 & 9,71 \\
\hline Diğer Borçlar & K10 & - & 11 & 11 & 12 & 10 & 12 & 12 & 11,31 \\
\hline Özkaynaklar & K11 & + & 1 & 5 & 4 & 4 & 2 & 4 & 2,94 \\
\hline Net Kar/Zarar & K12 & + & 5 & 3 & 3 & 3 & 1 & 2 & 2,54 \\
\hline
\end{tabular}

Yeni oluşan sıralamaya göre her bir uzman, ölçütleri önemlilik noktasında birbirleriyle karşılaştırmıştır. Ortaya çıkan 6 farklı karşılaştırma düzeni SWARA yöntemine göre değerlendirilmiştir. Nihayet bu değerlendirme neticesinde her bir uzmanın değerlendirmesine göre oluşan ölçüt ağırlıklarının geometrik ortalaması alınarak genel ölçüt ağırlıkları elde edilmiştir. Tablo 3 'de uzmanlar tarafından ölçütlerin ikili karşılaştırma değerleri ve genel ölçüt ağırlıkları verilmiştir. 
Tablo 3. Ölçütlerin Genel Ağırlıkları

\begin{tabular}{|l|c|c|c|c|c|c|c|c|c|c|}
\hline Ölçüt & & Sira & J & KV1 & KV2 & KV3s & KV4 $_{s}$ & KV5 & KV6s & W \\
\hline Faktoring Gelirleri & K1 & 1,73 & 1 & & & & & & & 0,109 \\
\hline Net Kar/Zarar & K12 & 2,54 & 2 & 0,05 & 0,00 & 0,05 & 0,05 & 0,05 & 0,05 & 0,104 \\
\hline Özkaynaklar & K11 & 2,94 & 3 & 0,00 & 0,00 & 0,10 & 0,00 & 0,00 & 0,10 & 0,101 \\
\hline Faktoring Alacakları & K2 & 3,03 & 4 & 0,00 & 0,00 & 0,00 & 0,00 & 0,00 & 0,15 & 0,099 \\
\hline Toplam Aktifler & K7 & 5,32 & 5 & 0,15 & 0,10 & 0,10 & 0,10 & 0,05 & 0,10 & 0,090 \\
\hline Alınan Krediler & K8 & 6,15 & 6 & 0,10 & 0,00 & 0,10 & 0,00 & 0,00 & 0,20 & 0,084 \\
\hline Duran Varlılar & K5 & 7,25 & 7 & 0,05 & 0,15 & 0,05 & 0,00 & 0,05 & 0,20 & 0,078 \\
\hline Takipteki Alacaklar & K4 & 7,55 & 8 & 0,00 & 0,00 & 0,00 & 0,15 & 0,10 & 0,25 & 0,072 \\
\hline Diğer Alacaklar & K3 & 7,57 & 9 & 0,00 & 0,20 & 0,05 & 0,00 & 0,10 & 0,10 & 0,067 \\
\hline $\begin{array}{l}\text { Maddi Olmayan Duran } \\
\text { Varlıklar }\end{array}$ & K6 & 8,23 & 10 & 0,05 & 0,00 & 0,00 & 0,05 & 0,00 & 0,05 & 0,066 \\
\hline Faktoring Borçlar1 & K9 & 9,71 & 11 & 0,10 & 0,00 & 0,00 & 0,00 & 0,00 & 0,10 & 0,064 \\
\hline Diğer Borçlar & K10 & 11,31 & 12 & 0,20 & 0,00 & 0,00 & 0,10 & 0,00 & 0,20 & 0,059 \\
\hline
\end{tabular}

\section{B. ARAS Yöntemi}

ARAS yöntemi ile şirketlerin 2013-2016 dönemi değerlendirilmesi sonucu oluşan performans değerleri Tablo 4'de verilmiştir.

Tablo 4. Faktoring Şirketlerinin ARAS Yöntemi İle Değerlendirilmesi

\begin{tabular}{|c|c|c|c|c|c|c|c|}
\hline Y11 & BSRFK & CRDFA & GARFA & HUZFA & LIDFA & SMRFT & YKFKT \\
\hline \multirow{2}{*}{2013} & 0,063 & 0,267 & 0,428 & 0,238 & 0,369 & 0,089 & 0,519 \\
\cline { 2 - 8 } & 7 & 4 & 2 & 5 & 3 & 6 & 1 \\
\hline \multirow{2}{*}{2014} & 0,082 & 0,256 & 0,504 & 0,211 & 0,486 & 0,059 & 0,478 \\
\cline { 2 - 8 } & 6 & 4 & 1 & 5 & 2 & 7 & 3 \\
\hline \multirow{2}{*}{2015} & 0,171 & 0,316 & 0,609 & 0,262 & 0,368 & 0,160 & 0,434 \\
\cline { 2 - 8 } & 6 & 4 & 1 & 5 & 3 & 7 & 2 \\
\hline \multirow{2}{*}{2016} & 0,144 & 0,225 & 0,509 & 0,231 & 0,474 & 0,147 & 0,495 \\
\cline { 2 - 8 } & 6 & 5 & 1 & 4 & 3 & 7 & 2 \\
\hline
\end{tabular}

Tablo 4 ve Şekil 1 birlikte değerlendirildiğinde; 2013 yılında 1. sırayı YKFKT, 2. sirayı GARFA ve 3. sırayı ise LIDFA şirketi alırken, şirketlerin siralamas $\quad$ YKFKT $>$ GARFA $>$ LIDFA $>$ CRFA $>$ HUZFA $>$ SMRFT $>$ BSRFK şeklinde olmuştur. 2014 yılında 1. sırayı GARFA, 2. sırayı LIDFA ve 3. sırayı da YKFKT almıştır. 2013 yılında 6. sıradaki SMRFT ile 7. sıradaki BSRFK, 2014 yılında yer değiştirmiş ve 2014 y1lı suralama GARFA>LIDFA>YKFKT> CRDFA $>$ HUZFA $>$ BSRFK $>$ SMRFT şeklinde gerçekleşmiştir. 2015 y1l itibariyle siralama GARFA $>$ YKFKT $>$ LIDFA $>$ CRDFA $>$ HUZFA $>$ BSRFK $>$ SMRFT şeklinde olmuş sadece bir önceki yılda 2. sıradaki LIDFA ile 3. sırada yer alan YKFKT şirketleri yer değiştirmiştir. 2016 yılında da sıralama bir önceki yıla benzer şekilde gerçekleşmiş sadece 2015 y1lında 4. ve 5. sırada yer alan CRDFK ve HUZFA şirketleri yer değişmiştir. Sıralama GARFA $>$ YKFKT $>$ LIDFA $>$ HUZFA>CRDFA>BSRFK > SMRFT şeklinde olmuştur.

2016 yılı dişarıda tutulursa tüm yıllar itibariyle CRDFA 4. ve HUZFA ise 5. sırayı almıştır. 2013 yılı dikkate alınmaz ise diğer yıllar itibariyle BSRFK ve SMRFT şirketlerinin sıralaması değişmemiş ve BSRFK 6. olurken SMRFT 7. ve 
son sırayı almıştır. Sadece 2013 yılında bu şirketler yer değiştirmiş ve SMRFT 6 . sırayı alırken BSRFK son sıraya yerleşmiştir.

Şekil 1 ve Şekil 2 birlikte değerlendirildiğinde tüm y1llar itibariyle en istikrarlı şirketin GARFA olduğu görülmektedir. İkinci sırayı YKFKT firmasının aldığı anlaşılmaktadır. YKFKT şirketini nispeten inişli çıkışlı seyir izlemesine rağmen LIDFA takip etmiştir. BSRFK ve SMRFT şirketlerinin ise 6. ve 7. sırada yer aldığı belirlenmiştir. 2016 yılı dikkate alınmazsa tüm yıllar itibariyle CRDFA 4. sıraya HUZFA ise 5. sıraya yerleşmiştir. Netice itibariyle tüm yıllar dikkate alındığında siralama, GARFA $>$ YKFKT $>$ LIDFA $>$ CRDFA $>$ HUZFA $>$ BSRFK $>$ SMRFT şeklinde olmuştur. Tüm yıllar itibariyle 4. sıradan itibaren sıralanan CRDFA, HUZFA, BSRFK ve SMRFT şirketlerinin eğilimlerinin bir birlerine çok benzediği görülmüş̧ür.

Şekil 1. ARAS Yöntemine Göre Faktoring Şirketlerinin Yıllara Göre Performans1

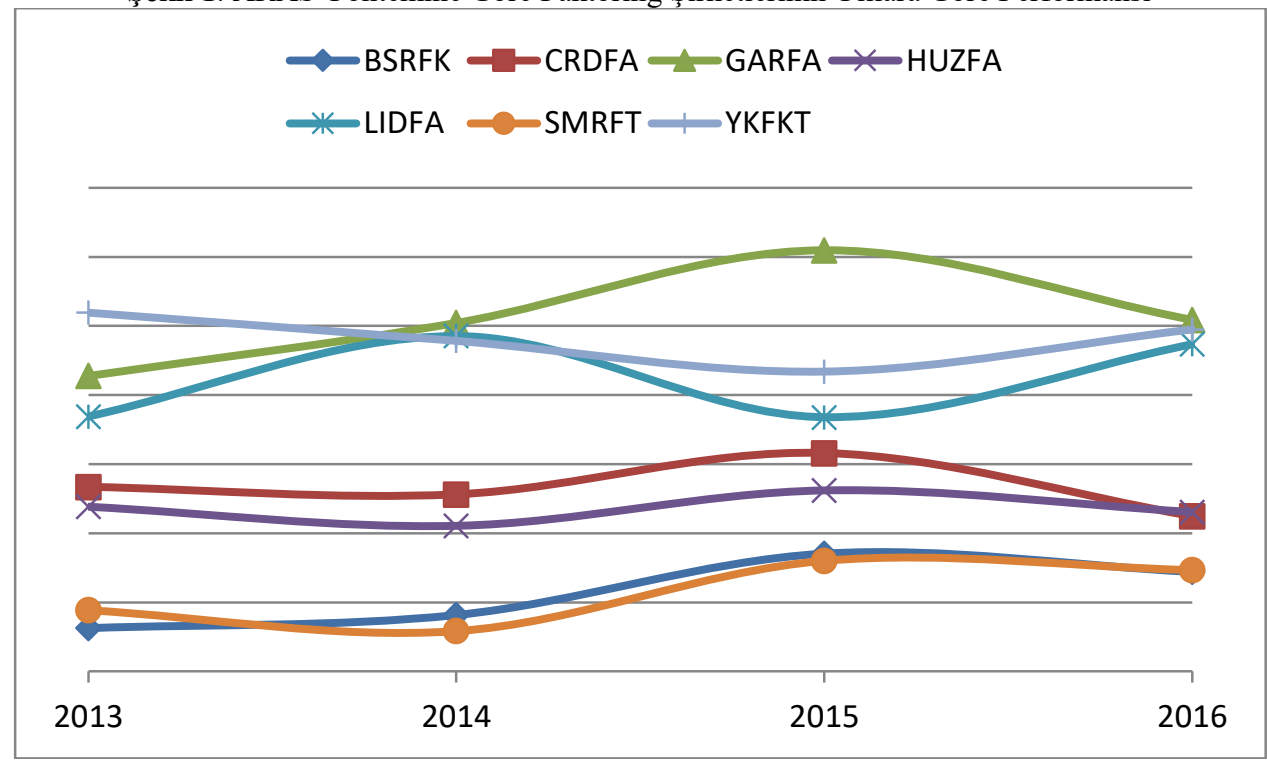


Şekil 2. ARAS Yöntemine Göre Faktoring Şirketlerinin Yı̆̆ılmış Sütun Grafiği

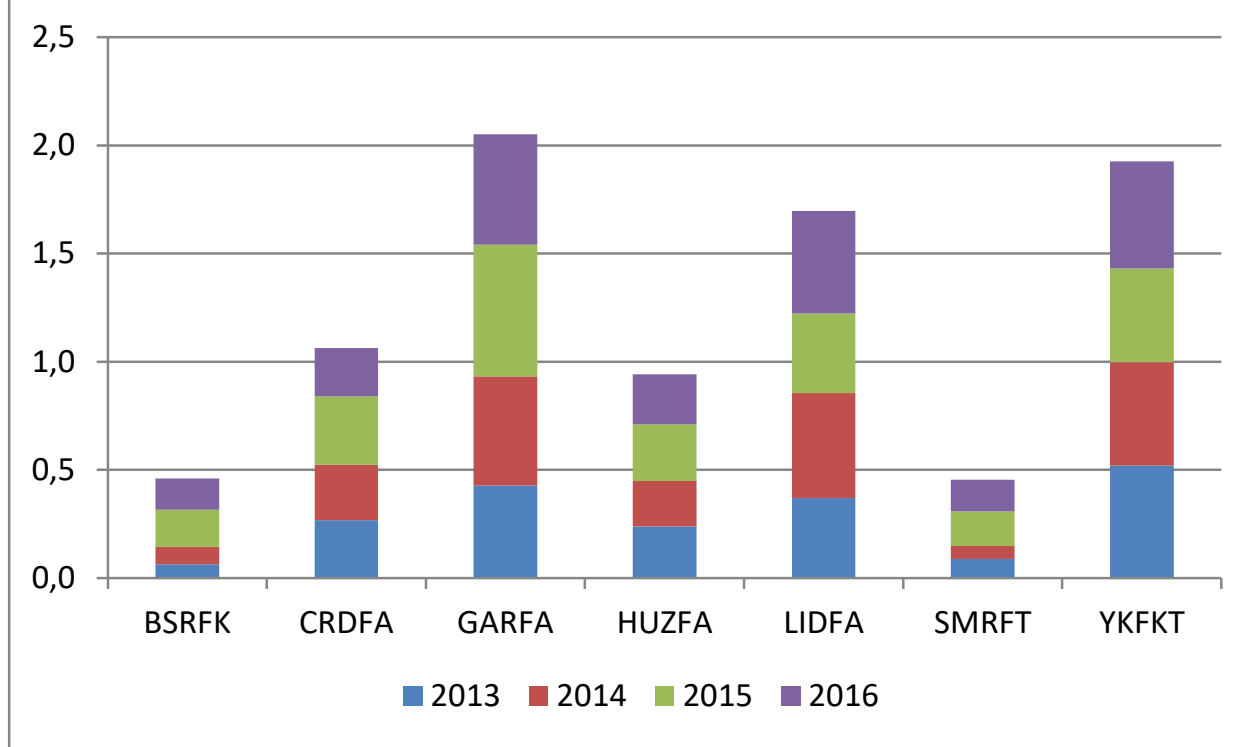

\section{MOORA Yöntemi}

MOORA yöntemi sonucunda faktoring şirketlerinin performans sıralaması Tablo 5'de verilmiştir. Tablo 5 ve Şekil 3 birlikte değerlendirildiğinde şirketlerin sıralamas1 yıllara göre büyük oranda benzerlik gösterdiği görülmüştür.

Tablo 5. Faktoring Şirketlerinin MOORA Yöntemi İle Performans Siralaması

\begin{tabular}{|c|c|c|c|c|c|c|c|}
\hline Y1l & BSRFK & CRDFA & GARFA & HUZFA & LIDFA & SMRFT & YKFKT \\
\hline \multirow{2}{*}{2013} & 0,024 & 0,151 & 0,232 & 0,026 & 0,203 & $-0,001$ & 0,373 \\
\cline { 2 - 8 } & 6 & 4 & 2 & 5 & 3 & 7 & 1 \\
\hline \multirow{2}{*}{2014} & 0,018 & 0,136 & 0,333 & 0,042 & 0,263 & $-0,013$ & 0,305 \\
\cline { 2 - 8 } & 6 & 4 & 1 & 5 & 3 & 7 & 2 \\
\hline \multirow{2}{*}{2015} & 0,047 & 0,191 & 0,336 & 0,047 & 0,211 & 0,046 & 0,224 \\
\cline { 2 - 8 } & 6 & 4 & 1 & 5 & 3 & 7 & 2 \\
\hline \multirow{2}{*}{2016} & 0,082 & 0,145 & 0,249 & 0,049 & 0,275 & 0,047 & 0,311 \\
\cline { 2 - 8 } & 5 & 4 & 3 & 6 & 2 & 7 & 1 \\
\hline
\end{tabular}


Şekil 3. MOORA Yöntemine Göre Faktoring Şirketlerinin Performans1

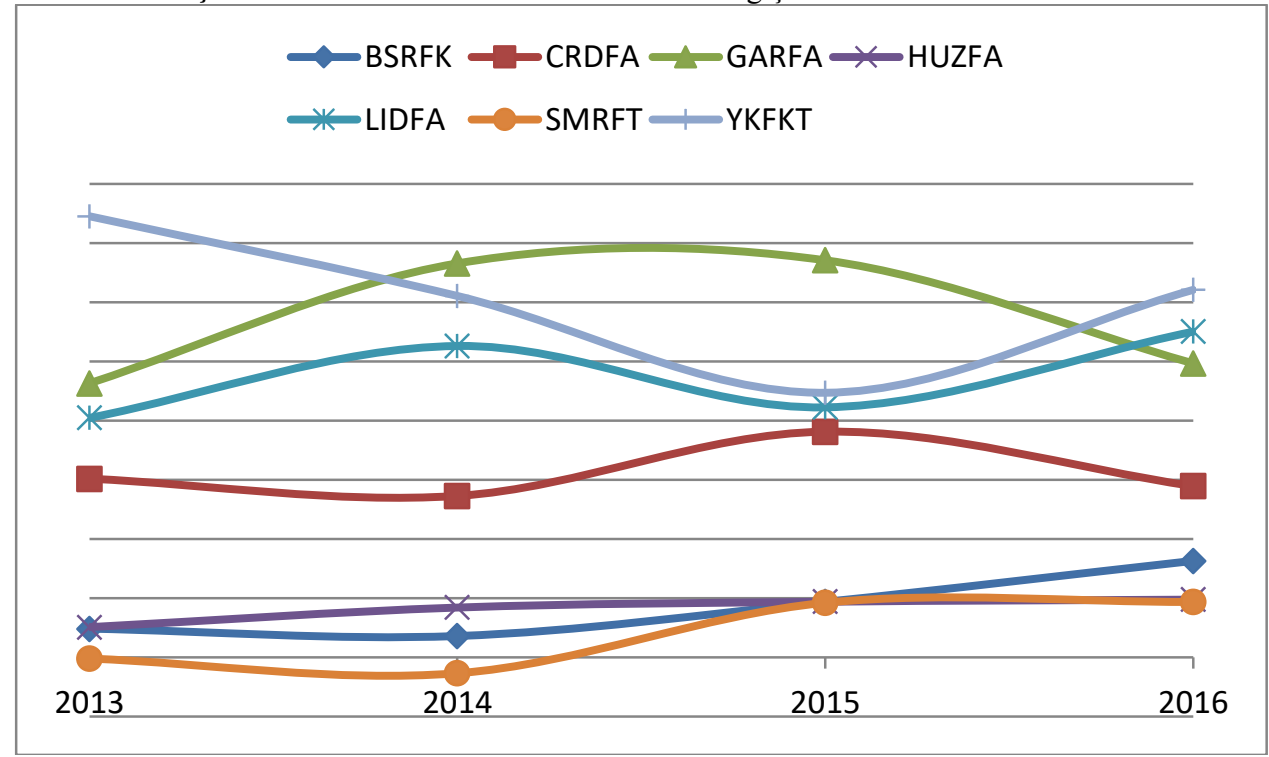

1. siray 2013 ve 2016 yılında YKFKT, 2014 ve 2015 y1lında ise GARFA şirketinin aldığı görülmüştür. LIDFA şirketi ise 2016 yılı dışındaki yıllarda 3. sırayı almıştır. Tüm yıllar itibariyle 4. sırayı CRDFA ve son sıra olan 7. sırayı ise SMRFT almıştır. 2013 ve 2014 yılında 5. ve 6. sırayı HUZFA ve BSRFK alırken, 2015 ve 2016 yılında bu şirketler yer değiştirmiştir. Tüm şirketler inişli-çıkışlı bir seyir izlerken, BSRFK şirketinin son sıralarda yer almasına rağmen istikrarlı olduğu görülmüştür.

YKFKT şirketi 2015 yılına kadar düşüş eğilimi gösterirken bu trendin 2015 den itibaren yukarıya doğru değiştiği görülmektedir. LIDFA ise üst sıralarda olmasına rağmen sürekli inişli-çıkışlı seyir gösterdiği anlaşılmaktadır. GARFA şirketinin 2015 y1lına kadar yükseliş eğilimi gösterirken bu tarihten itibaren düşüş trendine girdiği görülmektedir. CRDFA genel itibariyle inişli-çıkışlı bir seyir göstermesine rağmen 4. sırayı tüm yıllar itibariyle koruduğu belirlenmiştir. BSRFK şirketini genellikle 5 ya da 6 . sırayı korumasına rağmen az da olsa yükselme eğiliminde olduğu anlaşılmaktadır. HUZFA şirketi 2013 yılında 6. sırada iken sıralamasını 2016 yılında 4. sıraya çıkardığı belirlenmiştir. SMRFT şirketinin yıllara itibariyle sürekli olarak aşağıya doğru seyir izlediği anlaşılmaktadır.

Tüm yıllar itibariyle birinci sırayı GARFA, 2. sıray1 YKFKT ve 3. siray1 da LIDFA şirketinin aldığı belirlenmiştir. Tüm yıllar dikkate alındığında şirketlerin siralamas1 YKFKT $>$ GARFA $>$ LIDFA $>$ CRDFK $>$ BSRFK $>$ HUZFA $>$ SMRFT şeklinde gerçekleşmiştir. 
Şekil 4. MOORA Yöntemine Göre Şirketlerin Yı̆̆ılmış Sütun Grafiği

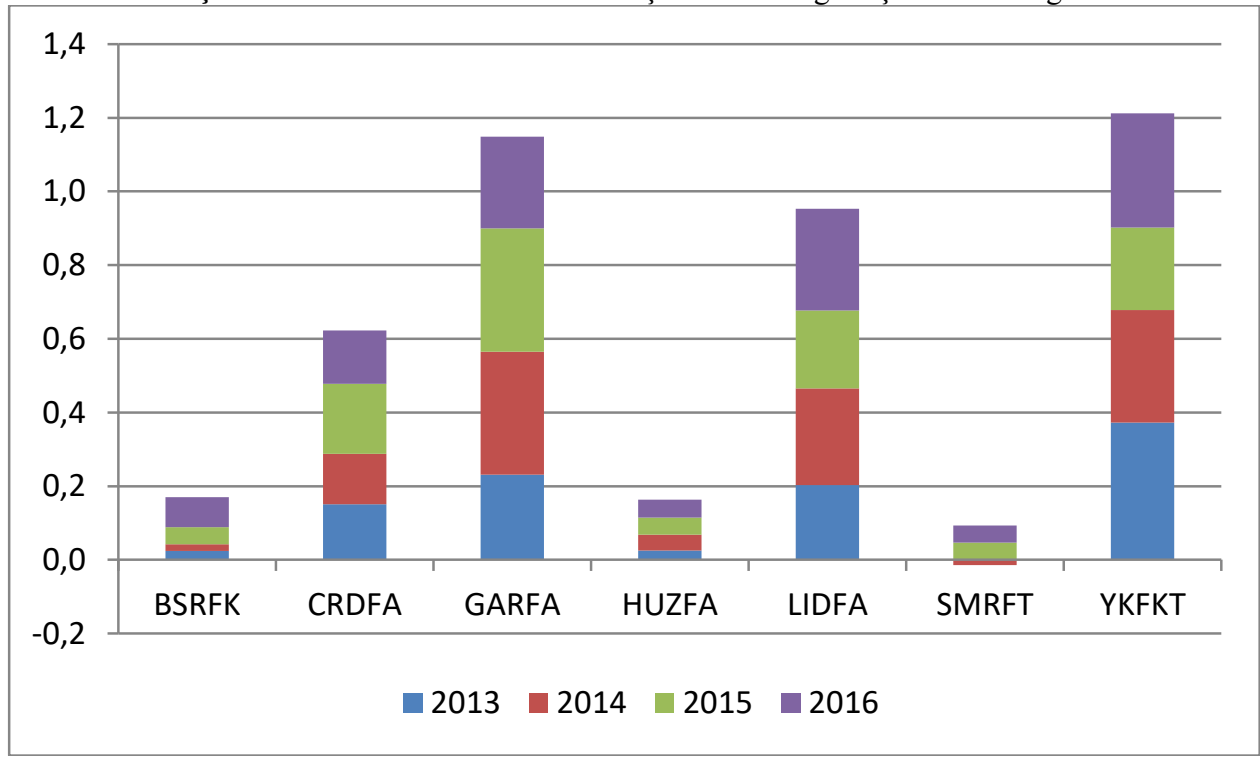

\section{TOPSIS Yöntemi}

TOPSIS yöntemi ile şirketlerin 2013-2016 dönemi değerlendirilmesi sonucu oluşan performans sıralaması Tablo 6'da verilmiştir.

Tablo 6. Faktoring Şirketlerinin TOPSIS Yöntemi İle Performans Siralaması

\begin{tabular}{|c|c|c|c|c|c|c|c|}
\hline Y11 & BSRFK & CRDFA & GARFA & HUZFA & LIDFA & SMRFT & YKFKT \\
\hline \multirow{2}{*}{2013} & 0,284 & 0,398 & 0,475 & 0,292 & 0,441 & 0,290 & 0,574 \\
\cline { 2 - 8 } & 7 & 4 & 2 & 5 & 3 & 6 & 1 \\
\hline \multirow{2}{*}{2014} & 0,273 & 0,394 & 0,582 & 0,300 & 0,501 & 0,249 & 0,565 \\
\cline { 2 - 8 } & 6 & 4 & 1 & 5 & 3 & 7 & 2 \\
\hline \multirow{2}{*}{2015} & 0,338 & 0,463 & 0,601 & 0,315 & 0,460 & 0,311 & 0,502 \\
\cline { 2 - 8 } & 5 & 3 & 1 & 6 & 4 & 7 & 2 \\
\hline \multirow{2}{*}{2016} & 0,376 & 0,407 & 0,520 & 0,335 & 0,547 & 0,329 & 0,567 \\
\cline { 2 - 8 } & 5 & 4 & 3 & 6 & 2 & 7 & 1 \\
\hline
\end{tabular}

Tablo 6 ve Şekil 5 birlikte analiz edildiğine 2013 yılı performans sıralaması YKFKT $>$ GARFA $>$ LIDFA $>$ CRDFA $>$ HUZFA $>$ SMRFT $>$ BSRFK şeklinde olmuştur. 2014 yılında sıralama, bir önceki yılda ilk iki sırada yer alan YKFKT ile GARFA şirketlerinin yer değiştirmesi neticesinde yeni siralama, GARFA $>$ YKFKT $>$ LIDFA $>$ CRDFA $>$ HUZFA $>$ BSRFK $>$ SMRFT $>\quad$ şeklinde olmuştur. 2015 yılında ilk iki ve son sıra yerini korurken bir önceki yıldaki 3. ile 4 ve 5. ile 6. suradaki şirketler yer değiştirmiştir. 2015 y1lı sıralaması GARFA $>$ YKFKT $>$ CRDFA $>$ LIDFA $>$ BSRFK $>$ HUZFA $>$ SMRFT şeklinde olmuştur. 2016 yılında 2015 yılındaki ilk dört sıradaki şirketlerin sıralamasında değişiklik görülürken son üç sıra değişmemiş ve sıralama şu şekilde 
gerçekleşmiştir:

YKFKT $>$ LIDFA $>$ GARFA $>$ CRDFA $>$ BSRFK $>$ HUZFA $>$ SMRFT.

Şekil 5. TOPSIS Yöntemine Göre Şirketlerin Performansı

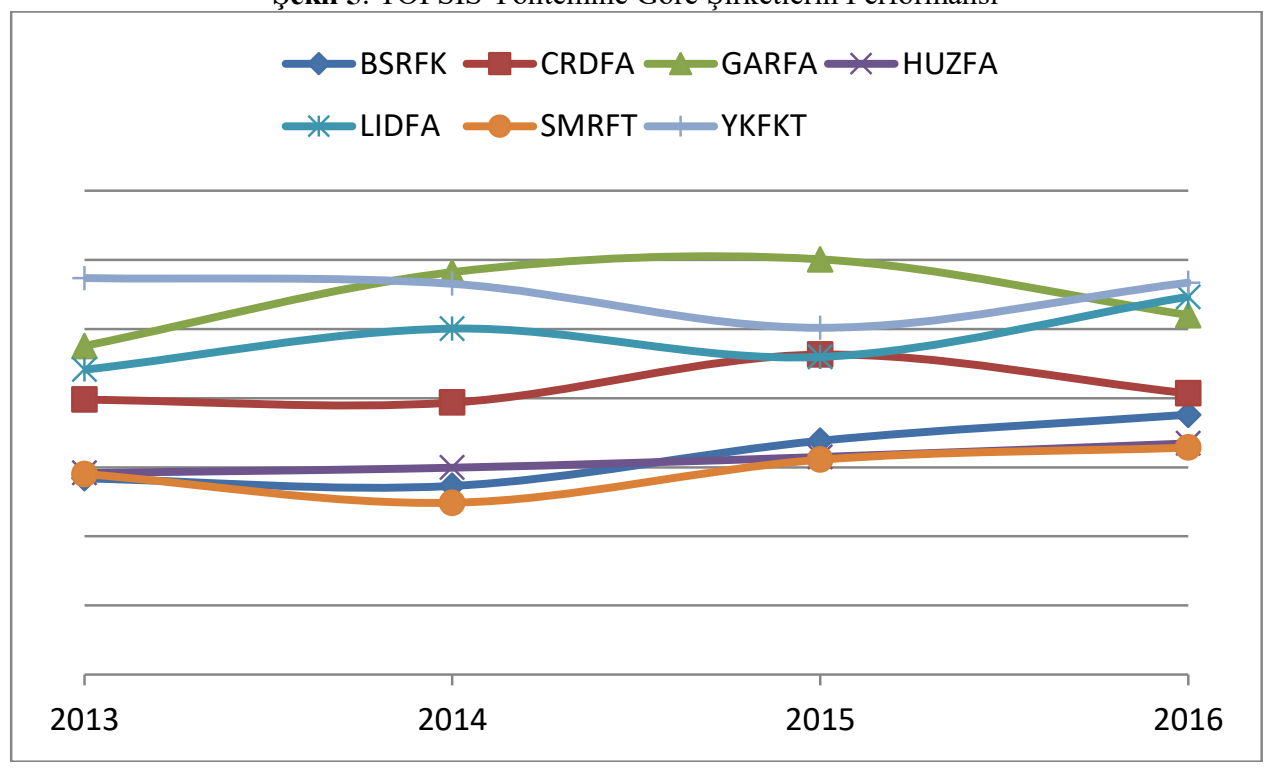

Tüm y1llar birlikte değerlendirildiğinde YKFKT ve GARFA şirketinin en başarılı şirket olduğu anlaşılmaktadır. Bu şirketleri LIDFA takip etmektedir. Son sıradaki şirketin ise SMRFT olduğu görülmektedir.

ARAS, MOORA ve TOPSIS yöntemleri sonuçları tüm yıllar dikkate alınarak karşılaştırıldığında her üç yönteme göre ilk iki sırayı YKFKT ve GARFA, 3. ve 4. sırayı ise LIDFA ve CRDFA şirketlerinin aldığı belirlenmiştir. BSRFK, MOORA ve TOPSIS yöntemine göre 5. siraya yerleşirken ARAS yöntemine göre 6. sırada kendine yer bulmuştur. Son sırayı her üç yönteme göre de SMRFT almıştır. 
Şekil 6. TOPSIS Yöntemine Göre Şirketlerin Yığılmış Sütun Grafiği

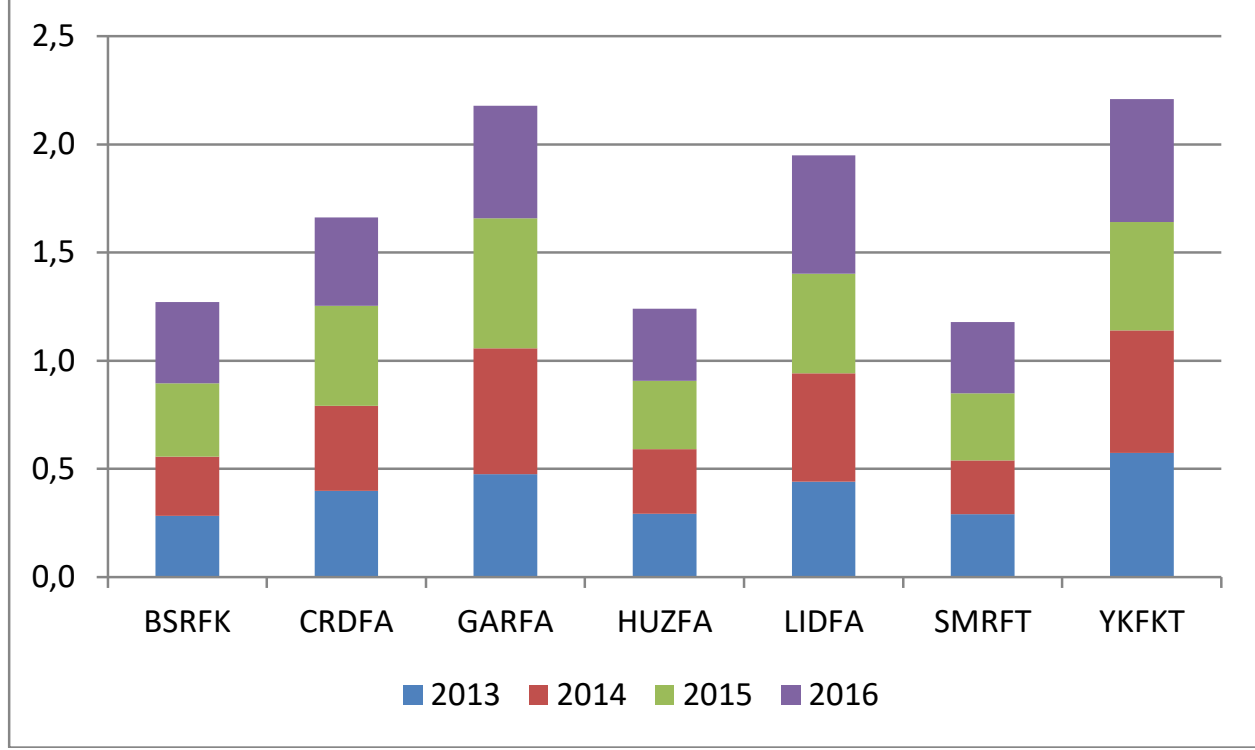

\section{SONUÇ}

Faktoring işlemleri gittikçe önem kazanan bir finansman aracıdır. Faktoring yoluyla finansman yöntemi ülke ekonomisine katkı sağlarken aynı zamanda firmalara da avantajlar sağlamaktadır. Giderek büyüyen bu sektörde sürecin önemli bir tarafi olan ve BİST'te işlem gören faktoring şirketleri ile çalışmak isteyen işletmeler için bu şirketlerinin performanslarını belirlemek önemli olmaktadir.

$\mathrm{Bu}$ çalışmada BİST'te işlem gören 7 adet faktoring şirketinin, literatür taraması sonucu belirlenen 12 ölçüte göre değerlendirilerek performans1 değerlendirilmiştir. Ölçüt ağıllıkları uzman değerlendirmeleri neticesinde SWARA yöntemine göre hesaplanmıştır. Bu şirketler, son yıllarda yaygın olarak ÇÖKV problemlerinin çözümünde uygulanan ARAS, MOORA ve TOPSIS yöntemlerine göre analiz edilmiştir. Her üç yönteme göre çıkan sonuçlar büyük benzerlik göstermiştir.

ARAS, MOORA ve TOPSIS yöntemi sonuçları tüm yıllar dikkate alınarak karşılaştırıldığında her üç yönteme göre ilk iki sırayı YKFKT ve GARFA, 3. ve 4. sırayı ise LIDFA ve CRDFA şirketlerinin aldığı belirlenmiştir. BSRFK, MOORA ve TOPSIS yöntemine göre 5. sıraya yerleşirken ARAS yöntemine göre 6. sırada kendine yer bulmuştur. Son sırayı her üç yönteme göre de SMRFT almıştır.

YKFKT, GARFA, LIDFA ve CRDFA şirketleri her üç yönteme göre de ilk dört sırayı almalarına karşın yıllar itibariyle performans değişiklikleri gösterdikleri belirlenmiştir. Her üç yönteme göre son sıralarda yer alan HUZFA, BSRFK ve SMRFT şirketlerinin çok az da olsa yukarıya doğru hareketliliği dikkat çekmektedir. 
YKFKT, GARFA, LIDFA ve CRDFA şirketlerinin üst sıralarda olmasına rağmen performans istikrarı elde etmek için gerekli kararları zaman geçirmeden almaları gerekir. HUZFA, BSRFK ve SMRFT şirketlerinin aza da olsa performanslarında iyileşme gözlemlenirken bu çabalarını daha çok artırmaları gerekmektedir.

Bu konuda ileride yapılacak çalışmalarda AHS, PROMETHEE, VIKOR ve WASPAS gibi yöntemler aynı ölçütlerle ya da yeniden belirlenecek ölçütlerle de uygulaması yapılabilir. Bu yöntemler, farklı ölçütlerle de tekrar uygulanabilir. Ortaya çıkan bulgular yorumlanabilir. Ayrıca belirsizlik durumları dikkate alınarak kullanılan ya da önerilen yöntemlerin bulanık uygulamaları da dikkate alınabilir.

\section{KAYNAKÇA}

Akel, V., Nuray, E., Sezayi, D. (2010). İMKB'de İşlem Gören Finansal Kiralama Şirketlerinin 20052008 Dönemi Finansal Performanslarının Değerlendirilmesi. Marmara Üniversitesi İktisadi ve İdari Bilimler Fakültesi Dergisi, 1, 271-292.

Akhavan, P., Barak, S., Maghsoudlou, H., Antuchevičienė, J. (2015). FQSPM-SWOT for strategic alliance planning and partner selection; case study in a holding car manufacturer company. Technological and Economic Development of Economy, 21(2), 165-185.

Alimardani, M., Zolfani, S. H., Aghdaie, M. H., Tamošaitienè, J. (2013). A novel hybrid SWARA and VIKOR methodology for supplier selection in an agile environment. Technological and Economic Development of Economy, 19(3), 533-548.

Antucheviciene, J., Zakarevicius, A., Zavadskas, E. K. (2011). Measuring congruence of ranking results applying particular MCDM methods. Informatica, 22(3), 319-338.

Arıkan Karg1, V. S. (2016). Supplier Selection for A Textile Company Using The Fuzzy TOPSIS Method. Journal of Management \& Economics, 23(3), 789-803.

Awasthi, A., Chauhan, S. S., Omrani, H. (2011). Application of fuzzy TOPSIS in evaluating sustainable transportation systems. Expert Systems with Applications, 38(10), 12270-12280.

Bağc1, H., Esmer, Y. (2016). PROMETHEE Yöntemi İle Faktoring Şirketi Seçimi. Beykent Üniversitesi Sosyal Bilimler Dergisi, 9(2), 116-129.

Baležentis, T., Streimikiene, D. (2017). Multi-criteria ranking of energy generation scenarios with Monte Carlo simulation. Applied Energy, 185, 862-871.

Banaitiene, N., Banaitis, A., Kaklauskas, A., Zavadskas, E. K. (2008). Evaluating the life cycle of a building: A multivariant and multiple criteria approach. Omega - International Journal of Management Science, 36 (3), 429-441

Banerjee, P. K. (2003). Performance Evaluation of Indian Factoring Business: A Study of SBI Factors and Commercial Services Limited, and Canbank Factors Limited. Vision: The Journal of Business Perspective, 7(1), 55-68.

Bloomberght:http://www.bloomberght.com/haberler/haber/1907784-leasing-faktoring-vefinansman-sirketlerinin-aktif-buyuklugu-100-milyari-asti. 26.03.2017

Brauers, W. K. M., Balezentis, A.i Balezentis, T., (2011). MULTIMORA forthe EU Member States updated with fuzzy number theory. Technological and Economic Development of Economy, 2, 259-290. http://dx.doi.Org/10.3846/20294913.2011.580566

Brauers, W. K. M., Zavadskas, E. K. (2012). Robustness of MULTIMOORA: a method for multiobjective optimization. Informatica, 23(1), 1-25.

Brauers, W. K. M., Zavadskas, E. K., (2006). The MOORA method and its application to privatization in a transition economy. Control and Cybernetics, 35(2), 445.

Brauers, W. K. M., Zavadskas, E. K., Peldschus, F.,Turskis, Z. (2008). Multi objective decision making for road design. Transport, 23(3),183-193.

Brauers, W.K.M, Zavadskas, E.K., Kildiene, S. (2014). Was the Construction Sector in 20 European Countries Anti-cyclical during the Recession Years 2008-2009 as Measured by Multicriteria Analysis (MULTIMOORA). Procedia Computer Science, 31,949-956. 
Causa, H., Brauers, W.K.M. (2014). Location of a seaport by MOORA optimization. In: Advanced Logistics and Transport (ICALT), 2014 International Conference on. IEEE, 275-280

Chakraborty, S (2011). Applications of the MOORA method for decision making in manufacturing environment. The International Journal of Advanced ManufacturingTechnology, 54(9-12), 1155-1166.

Chamodrakas, I., Martakos, D.(2012). A utility-based fuzzy TOPSIS method for energy efficient network selection in heterogeneous wireless Networks. Applied Soft Computing, 12(7),1929-1938.

Chatterjee, N.,Bose, G. (2013). Selection of vendors for wind farm under fuzzy MCDM environment. International Journal of Industrial Engineering Computations, 4(4), 535-546.

Chatterjee, P., Athawale, V. M., Chakraborty, S. (2011). Materials selection using complex propoptional assessment and evaluation of mixed data methods. Matherials \&Design, 32(2), 851-860

Chatterjee, P.,Chakraborty, S. (2012). Material selection using preferential ranking methods. Materials \& Design, 35, 384-393.

Cheng, S., Chan, C. W., Huang, G. H. (2002).Using multiple criteria decision analysis for supporting decisions of solid waste management. Journal of Environmental Science and Health, Part A, 37(6), 975-990.

Chu, J., Su, Y. (2012). The application of TOPSIS method in selecting fixed seismic shelter for evacuation in cities. Systems Engineering Procedia, 3,391-397.

Darji, V. P., Rao, R. V. (2014). Intelligent multi criteria decision making methods for material selection in sugar industry. Procedia Materials Science, 5, 2585-2594.

Das, M. C., Sarkar, B.,Ray, S. (2012). A framework to measure relative performance of Indian technical institutions using integrated fuzzy AHP and COPRAS methodology. SocioEconomic Planning Sciences, 46(3), 230-241.

Datta, S., Beriha, G. S., Patnaik, B., Mahapatra, S. S. (2009). Use of compromise ranking method for supervisor selection: A multi-criteria decision making (MCDM) approach. International Journal of Vocational and Technical Education, 1(1), 7-13.

Dehnavi, A., Aghdam, I. N., Pradhan, B.,Varzandeh, M. H. M. (2015). A new hybrid model using step-wise weight assessment ratio analysis (SWARA) technique and adaptive neuro-fuzzy inference system (ANFIS) for regional landslide hazard assessment in Iran. Catena, 135, $122-148$.

Ece, N., Özdemir, F. (2011). Halka Açık Finansal Kiralama ve Faktoring Şirketlerinin Performans Ölçümü ve Analizinde Kullanılan EVA ve TOPSIS Yöntemlerinin Hisse Senedi Değerleri ile Karşılaştırmalı Analizi. Finans Politik \& Ekonomik Yorumlar.48(561),.83-95.

Ergül, N., Akel, V. (2010). Finansal Kiralama Şirketlerinin Finansal Performansının TOPSIS Yöntemi ile Analizi. MÖDAV Dergisi, 3, 91-118.

FCI: https://fci.nl/en/about-factoring/statistics. 26.03.2017

FKB: https://www.fkb.org.tr/sektorler/faktoring/. 25.03.2017

Gadakh, V. S., Shinde, V. B., Khemnar, N. S. (2013). Optimization of welding process parameters using MOORA method. The International Journal of Advanced Manufacturing Technology, 69(9-12), 2031-2039.

Ghadikolaei, A. S., Esbouei, S. K. (2014). Integrating Fuzzy AHP and Fuzzy ARAS for evaluating financial performance. Boletim da Sociedade Paranaense de Matemática, 32(2), 163-174.

Ghadikolaei, A. S., Esbouei, S. K., Antuchevičienè, J. (2014). Applying fuzzy MCDM for financial performance evaluation of Iranian companies. Technological and Economic Development of Economy, 20(2), 274-291.

Ghorabaee, M. K., Amiri, M., Sadaghiani, J. S., Goodarzi, G. H. (2014). Multiple criteria group decision-making for supplier selection based on COPRAS method with interval type-2 fuzzy sets. The International Journal of Advanced Manufacturing Technology, 75(5-8), 1115-1130. 
Günay, B. (2013). Türkiye'de Leasing Ve Leasing Şirketlerinin Etkinliklerinin VZA İle Ölçülmesi. (Yayınlanmamış Yüksek Lisans Tezi). Karadeniz Teknik Üniversitesi, Sosyal Bilimler Enstitüsü, Trabzon.

Hasan Aghdaie, M., Hashemkhani Zolfani, S., Zavadskas, E. K. (2013). Decision making in machine tool selection: An integrated approach with SWARA and COPRAS-G methods. Engineering Economics, 24(1), 5-17.

İnal, Z.(2006). Faktoring Uygulamaları ve İşletmelerin Finansal Yapılarına Etkisi. (Yayınlanmamış Yüksek Lisans Tezi), İnönü Üniversitesi, Sosyal Bilimler Enstitüsü, Malatya.

Janekova, J. (2012). Faktoring-Alternative Source of A Company. Annals of the Faculty of Engineering Hunedoara. International Journal of Engineering, 10 (3), 303-306.

Kaklauskas, A., Zavadskas, E. K., \& Raslanas, S. (2005). Multivariant design and multiple criteria analysis of building refurbishments. Energy and Buildings, 37(4), 361-372.

Kaklauskas, A., Zavadskas, E. K., Naimaviciene, J., Krutinis, M., Plakys, V., Venskus, D. (2010). Model for a Complex Analysis of Intelligent Built Environment. Automation in Construction, 19(3), 326-340.

Karabašević, D., Stanujkić, D., \& Urošević, S. (2015). The MCDM model for personnel selection based on SWARA and ARAS methods. Management časopis za teoriju i praksu menadžmenta, 77, 43-52.

Karabašević, D., Stanujkić, D., Urošević, S., Maksimović, M. (2016). An approach to personnel selection based on SWARA and WASPAS methods. Bizinfo (Blace) Journal of Economics, Management and Informatics, 7(1), 1-11.

Karabašević, D., Zavadskas, E. K., Turskis, Z., Stanujkic, D. (2016). The framework for the selection of personnel based on the SWARA and ARAS methods under uncertainties. Informatica, 27(1), 49-65.

Karande, P. , Chakraborty, S. (2012). Application of multi-objective optimization on the basis of ratio analysis (MOORA) method for materials selection, Materials \& Design, 37, 317-324.

Kaur, H., Dhaliwal, N. K. (2014). Financial Analysis of Factoring Companies in India: A Study of SBI Global Factors and Canbank Factors. International Journal of Research in Management, Science \& Technology, 2(1), 30-34.

Keršulienė, V., Turskis, Z. (2011). Integrated fuzzy multiple criteria decision making model for architect selection. Technological and Economic Development of Economy, 17(4), 645-666.

Keršulienė, V., Turskis, Z. (2014). An integrated multi-criteria group decision making process: selection of the chief accountant. Procedia-Social and Behavioral Sciences, 110, 897-904.

Keršulienė, V., Zavadskas, E. K., Turskis, Z. (2010). Selection of rational dispute resolution method by applying new step-wise weight assessment ratio analysis (SWARA). Journal of Business Economics and Management, 11(2), 243-258.

Koch, S. (2015). Efects of Shareholder Groups on the Faktoring Institutions Profitability: Evidence from Germany. International Journal of Economics and Finance, 7 (11), 39-51.

Kouchaksaraei, R.H, Zolfani, S.H, Golabchi,M.(2015). Glasshouse locating based on SWARACOPRAS approach. International Journal of Strategic Property Management,19(2),111122

Kracka, M., Brauers, W. K. M, Zavadskas, E.Z. (2010). Ranking heating losses in a building by applying the MULTIMOORA. Inzinerine Ekonomika-Engineering Economics, 21(4), 352-359.

$\mathrm{Li}$, Q. (2016). Weighted absolute degree of grey incidence with TOPSIS and its application. Grey Systems: Theory and Application, 6(2), 281-291.

Liao, C. N., Fu, Y. K., Wu, L. C. (2016). Integrated FAHP, ARAS-F and MSGP methods for green supplier evaluation and selection. Technological and Economic Development of Economy, 22(5), 651-669.

Liou, J. J., Tamošaitienè, J., Zavadskas, E. K.,Tzeng, G. H. (2016). New hybrid COPRAS-G MADM Model for improving and selecting suppliers in green supply chain management. International Journal of Production Research, 54(1), 114-134. 
Liu, H. C., You, J. X., Lu, C., Shan, M. M. (2014). Application of interval 2-tuple linguistic MULTIMOORA method for health-care waste treatment technology evaluation and selection. Waste Management, 34(11), 2355-2364.

Mandal, U. K., \&Sarkar, B. (2012). Selection of Best Intelligent Manufacturing System Under Fuzzy MOORA Conflicting MCDM Environment. International Journal Of Engineering Technology and Advanced Engineering, 2(9), 301-310.

Mavi, R. K., Goh, M., Zarbakhshnia, N. (2017). Sustainable third-party reverse logistic provider selection with fuzzy SWARA and fuzzy MOORA in plastic industry. The International Journal of Advanced Manufacturing Technology, 1-18.

Medineckiene, M., Zavadskas, E. K., Björk, F., Turskis, Z. (2015). Multi-criteria decision-making system for sustainable building assessment/certification. Archives of Civil and Mechanical Engineering, 15(1), 11-18.

Mousavi-Nasab, S. H., Sotoudeh-Anvari, A. (2017). A comprehensive MCDM-based approach using TOPSIS, COPRAS and DEA as an auxiliary tool for material selection problems. Materials \& Design, 121, 237-253.

Mulliner, E., Malys, N., Maliene, V. (2016). Comparative analysis of MCDM methods for the assessment of sustainable housing affordability. Omega, 59, 146-156.

Nguyen, H. T., Dawal, S. Z. M., Nukman, Y., Aoyama, H., Case, K. (2015). An integrated approach of fuzzy linguistic preference based AHP and fuzzy COPRAS for machine tool evaluation. PloS one, 10(9), 1-24.

Nuuter, T., Lill, I., Tupenaite, L. (2015). Comparison of housing market sustainability in European countries based on multiple criteria assessment. Land Use Policy, 42, 642-651.

Ölmez, İ. (2012). Türkiye'de Faktoring ve Faktoring İşlemlerinin Muhasebeleștirilmesi. (Yayınlanmamış Yüksek Lisans Tezi). İstanbul Aydın Üniversitesi, İstanbul.

Öncel, A. (1991). Factoring'in Uluslararast Yapısı. ISSO Dergisi

Özbek, A. (2013). Performance evaluation of learning management system. NWSA-Education Sciences, 8 (2),156-178. http://dx.doi.org/10.12739/NWSA.2013.8.2.1C0580

Özbek, A. (2014). Sivil Toplum Kuruluşlarında Yöneticilerin Bütünleşik Bir Yaklaşım İle Seçilmesi. International Journal of Engineering Research and Development, 6(2), 4-15.

Özbek, A. (2015a). Akademik Birim Yöneticilerinin MOORA Yöntemiyle Seçilmesi: Kırıkkale Üzerine Bir Uygulama. Erciyes Üniversitesi Sosyal Bilimler Enstitüsü Dergisi, 38(1), 1-18.

Özbek, A. (2015b). Efficiency Analysis of Foreign-Capital Banks in Turkey by OCRA and MOORA. Research Journal of Finance and Accounting, 6 (13), 21-30.

Özbek, A. (2015c). Supplier Selection with Fuzzy TOPSIS. Journal of Economics and Sustainable Development, 6(18), 114-125.

Özbek, A., Eren, T. (2013). Çok Ölçütlü Karar Verme Teknikleri İle Hizmet Sağlayıcı Seçimi. Akademik Bakış Dergisi, 36,1-22.

Özbek, A. (2017). Çok Kriterli Karar Verme Yöntemleri ve Excel İle Problem Çözümü. 1. Bask1, Ankara: Seçkin Yayıncılık.

Özdemir, Z. (2005). Dış Ticaret Finansman Tekniklerinden Faktoring ve Forfaiting İşlemleri. Kocaeli Üniversitesi Sosyal Bilimler Enstitüsü Dergisi, 10 (2), 194-224.

Pazand, K., Hezarkhani, A., Ataei, M. (2012). Using TOPSIS approaches for predictive porphyry Cu potential mapping: A case study in Ahar-Arasbaran area (NW, Iran). Computers \& Geosciences, 49:62-71.

Rabbani, A., Zamani, M., Yazdani-Chamzini, A., Zavadskas, E. K. (2014). Proposing a new integrated model based on sustainability balanced scorecard (SBSC) and MCDM approaches by using linguistic variables for the performance evaluation of oil producing companies. Expert Systems with Applications, 41(16), 7316-7327.

Ravaş, O.C., David, A. (2010). Factoring Agreement-Financing Method For The Companies In Lack of Cash-Flow. Annals of the University of Petroşani, Economics, 10 (4), 289-296

Ravi, V. (2011). Selection of third-party reverse logistics providers for End-of-Life computers using TOPSIS-AHP based approach. International Journal of Logistics Systems and Management, 11(1):24-37. 
Reza, S., Majid, A. (2013). Ranking Financial Institutions Based on of Trust in online banking Using ARAS and ANP Method. International Research Journal of Applied and Basic Sciences, 6(4), 415-423.

Ruzgys, A., Volvačiovas, R., Ignatavičius, Č., Turskis, Z. (2014). Integrated evaluation of external wall insulation in residential buildings using SWARA-TODIM MCDM method. Journal of Civil Engineering and Management, 20(1), 103-110.

Shariati, S., Yazdani-Chamzini, A., Salsani, A., Tamošaitienè, J. (2014). Proposing a New Model for Waste Dump Site Selection: Case Study of Ayerma Phosphate Mine. Engineering Economics, 25(4), 410-419.

Sindhu, S., Nehra, V., Luthra, S. (2017). Investigation of feasibility study of solar farms deployment using hybrid AHP-TOPSIS analysis: Case study of India. Renewable and Sustainable Energy Reviews, 73, 496-511.

Şişman, B., Doğan, M. (2016). Türk Bankalarının Finansal Performanslarının Bulanık AHP ve Bulanık MOORA Yöntemleri İle Değerlendirilmesi. Yönetim ve Ekonomi: Celal Bayar Üniversitesi İktisadi ve İdari Bilimler Fakültesi Dergisi, 23(2), 353-371.

Sliogeriene, J., Kaklauskas, A., Zavadskas, E.K., Bivainis, J., Seniut, M. (2009). Environment factors of energy companies and their effect on value: analysis model and applied method. Technological and Economic Development of Economy, 15 (3), 490-521.

Sliogeriene, J., Turskis, Z., Streimikiene, D. (2013). Analysis and choice of energy generation technologies: The multiple criteria assessment on the case study of Lithuania. Energy Procedia, 32, 11-20.

Stratejifactoring: http://www.stratejifactoring.com.tr/factoring_nedir.html

Štreimikiene, D., Šliogerienè, J., Turskis, Z. (2016). Multi-criteria analysis of electricity generation technologies in Lithuania. Renewable Energy, 85, 148-156.

Tiryaki, B. (2006). Factoring İşlemi ve Factoring İşleminin Hukuki Niteliği. Dokuz Eylül Üniversitesi Hukuk Fakültesi Dergisi, 8(2), 189-214.

Tosun, D. (2007). Bir İhracat Finansman Yöntemi Olarak Faktoring: Dünya ve Türkiye Uygulamast. (Yayınlanmamaış Yüksek Lisans Tezi), Kocaeli Üniversitesi, Kocaeli.

Tupenaite, L., Zavadskas, E. K., Kaklauskas, A., Turskis, Z., Seniut, M. (2010). Multiple criteria assessment for built and human environment. Journal of Civil Engineering and Management, 16(2), 257-266.

Uzsilaityte, L., Martinaitis, V. (2010). Search for optimal solution of public building renovation in terms of life cycle. Journal of Environment Enginnering and Landscape Management, $18(2), 102-110$

Vafaeipour, M., Zolfani, S. H., Varzandeh, M. H. M., Derakhti, A., Eshkalag, M. K. (2014). Assessment of regions priority for implementation of solar projects in Iran: New application of a hybrid multi-criteria decision making approach. Energy Conversion and Management, 86, 653-663.

Varmazyar, M., Dehghanbaghi, M., Afkhami, M. (2016). A novel hybrid MCDM model for performance evaluation of research and technology organizations based on BSC approach. Evaluation and Program Planning, 58, 125-140.

Vytautas, B., Marija, B., Vytautas, P. (2015). Assessment of neglected areas in Vilnius city using MCDM and COPRAS methods. Procedia Engineering, 122, 29-38.

$\mathrm{X} 1, \mathrm{~F}$. ve Zhang, L. (2011). A personnel selection model based on TOPSIS. Management science and Engineering, 5(3), 07-110.

Zamani, M., Rabbani, A., Yazdani-Chamzini, A., Turskis, Z. (2014). An integrated model for extending brand based on fuzzy ARAS and ANP methods. Journal of Business Economics and Management, 15(3), 403-423.

Zavadskas, E. K., Kaklauskas, A. (1996). Multicriteria Evaluation of Building (Pastatu sistemotechninis ịvertinimas). Vilnius: Technika

Zavadskas, E. K., Kaklauskas, A., Turskis, Z., Tamosaitiene, J. (2008a). Selection of the effective dwelling house walls by applying attributes values determined at intervals. Journal of Civil Engineering and Management, 14(2), 85-93. 
Zavadskas, E. K., Kaklauskas, A., Turskis, Z., Tamosaitiene, J. (2008b.) Contractor selection multiattribute model applynig COPRAS method with grey interval numbers. in 20th International Conference/Euro Mini Conference on Continuous Optimization and Knowledge-Based Technologies (EurOPT 2008), May 20-23, 2008 Neringa, Lithuania. Vilnius: Technika, 241-247.

Zavadskas, E. K., Kaklauskas, A., Turskis, Z., Tamosaitiene, J., Kalibatas, D. (2008c). Assessment of indoor environment applynig COPRAS method with attributes determined in intervals, in 7th International Conference on Environmental Engineering, May 22-23, 2008 Vilnius, Lithuania, 1-3, 907-912.

Zavadskas, E. K., Sušinskas, S., Daniūnas, A., Turskis, Z., Sivilevičius, H. (2012). Multiple criteria selection of pile-column construction technology. Journal of Civil Engineering and Management, 18(6), 834-842.

Zavadskas, E. K., Vainiūnas, P., Turskis, Z., Tamošaitienè, J. (2012). Multiple criteria decision support system for assessment of projects managers in construction. International Journal of Information Technology \& Decision Making, 11(02), 501-520.

Zavadskas, E.K., Turskis, Z. (2010). A new additive ratio assessment (ARAS) method in multicriteria decision-making. Technological and Economic Development of Economy, 16(2), 159-172

Zolfani, S. H., Bahrami, M. (2014). Investment prioritizing in high tech industries based on SWARACOPRAS approach. Technological and Economic Development of Economy, 20(3), 534553 Zolfani, S. H., Pourhossein, M., Yazdani, M., Zavadskas, E. K. (2017). Evaluating construction projects of hotels based on environmental sustainability with MCDM framework. Alexandria Engineering Journal.

Zolfani, S. H., Zavadskas, E. K. (2013). Sustainable development of rural areas' building structures based on local climate. Procedia Engineering, 57, 1295-1301.

\section{SUMMARY}

The need for factoring companies, which play an important role in domestic and foreign financing of trade, is increasing. Determining the most appropriate factoring company for businesses seeking factoring services is a Multi-Criteria Decision-Making (MCDM) problem where many factors must be taken into consideration. For this reason, it is very important for the enterprises to choose the factoring company which is best suited to their financing policy.

In this study, 7 factoring companies traded in Borsa Istanbul (BIST) were evaluated in terms their financial aspects taking into consideration the balance sheet and income tables of the years 2013-2016. The data was obtained from the Public Disclosure Platform (KAP). The criteria for the evaluation of the companies were determined as the result of literature review.

These criteria are: factoring income (K1), factoring receivables (K2), other receivables (K3), non-performed receivables (K4), fixed assets (K5), intangible fixed assets (K6), total assets (K7), accepted credits (K8), factoring debts (K9), other debts (K10), equity (K11), and net profit/loss (K12). K4, K9 and K10 went in the direction of minimization, while the others went in the direction of maximization. The criteria were first sorted by 6 experts from top to bottom according to their importance. The geometric mean of these orders was taken and a general ranking was obtained by rearranging the criteria from top to bottom according to importance by new values. The criteria in the general order were compared by each expert. Based on the comparison of each expert, criteria weights were determined by the Step-wise Weight Assessment Ratio Analysis (SWARA) 
method. The general criteria weights were obtained by calculating the geometric mean of the calculated criteria weights. The general criteria weights were K1 $(0,109), \mathrm{K} 12(0,104), \mathrm{K} 11(0,101), \mathrm{K} 2(0,99), \mathrm{K} 7(0,90), \mathrm{K} 8(0,084), \mathrm{K} 5(0,078)$, K4 K3 (0.067), K6 (0.66), K9 (0.064) and K10 (0.059).

In the evaluation of the companies according to the criteria, Additive Ratio Assessment (ARAS), Multi-Objective Optimization on the basis of Ratio Analysis (MOORA) and Technique for Order of Preference (TOPSIS) (Multi Criteria Decision Making methods) were used in an integrated manner.

The results of each method were analyzed and the performances of the companies according to years were calculated. According to the ARAS method, the first three were GARFA>LIDFA> YKFKT and the last two were BSRFK and SMRFT companies. CRDFK and HUZFA companies were in the 4th and 5th places. According to the MOORA method, the rankings of the companies did not change significantly and while YKFKT $>$ GARFA $>$ LIDFA companies took the first three places, the rankings of the other companies did not change. The TOPSIS method produced similar results. YKFKT $>$ GARFA $>$ LIDFA companies were the first three as in the MOORA, while the last two were BSRFK and SMRFT. As in other methods, the 4th and 5th places were taken by CRDFK and HUZFA.

When the years 2013-2016 are assessed holistically, the first three are YKFKT, GARFA and LIDFA according to MOORA and TOPSIS methods; according to ARAS method, GARFA, LIDFA and YKFKT companies have taken the first three places. According to all methods, BSRFK and SMRFT are the last two, and CRDFK and HUZFA are in the 4th and 5th places.

YKFKT, GARFA, LIDFA and CRDFA companies appear to perform differently over the years despite their high rankings. The companies need to take the necessary precautions in a timely manner to stabilize their performances. Although HUZFA, BSRFK and SMRFT companies are improving, they need to increase their efforts even more. 